\title{
Influence Networks Relating to Health Knowledge Among Nairobi's Micro-Retailers and Their Clients
}

\author{
Jarret Cassaniti, Kuor Kumoji, Frederick Rariewa, Saori Ohkubo and Olamide Oyenubi \\ Johns Hopkins Center for Communication Programs, Baltimore, USA \\ jarret.cassaniti@jhu.edu
}

\begin{abstract}
TRANSFORM, founded in 2015 by Unilever and the UK's Department for International Development, supports several social enterprises by combining public sector resources with private sector technical capabilities and networks to support innovative social enterprises. Digital programs have enabled social enterprise partnerships to expand the reach of their initiatives to broader audiences including specifically defined groups that hitherto were untapped or difficult to reach. Unilever partnered with TRANSFORM and Every1Mobile to develop UJoin and UAfya in informal settlements of Nairobi, Kenya. UJoin is a social enterprise initiative for promoting business growth among underserved neighborhood shops called dukas. UAfya focuses on young expectant and new mothers, and women interested in family and maternal health topics. Each initiative uses an online community network to discuss and improve knowledge and behaviors regarding livelihoods and health. Online communities provide opportunities to reach specific groups with targeted behavior change messages and campaigns. However, little systematic knowledge is currently available on how to develop, and scale-up effective behavior change programs for digital communities in low-income markets. There is also little information about key guiding principles and best practices that underlie successful digital and online, social networking models. A systematic and participatory tool known as Net-Map was used to explore and understand potential frameworks for establishing digital-based communitydriven partnerships with the private sector for health promotion through behavior change. The Net-Map approach was used to help individuals and groups clarify their view of a situation (including networks and power structures), foster discussion, and develop a strategic approach to their networking activities. Eight Net-Maps were constructed, stratified by groups based on location and digital platform. Each map was constructed by an average of 9-10 people for a total of 76 participants. Seventy-six participants identified actors - stakeholders and groups of people involved - and influential links - ways actors are connected - through the Net-Map activity. Among UAfya participants, local government, family, and friends, and the media were identified as the most important actor types. A comparison of the discussions associated with the creation of the maps by UAfya members shows that the two most important link types are conflict, and collaboration/partnership. Among UJoin participants, the three most important actor types were local government, business and financial institutions, and customers. UJoin members identified regulation, and conflict and competition, collaboration and, information sharing as key links between actors. Recommendations based on findings support a vision for scale-up of the UJoin and UAfya programs through accreditation and branding of a novel type of duka. Shop keepers would be trained and knowledgeable to provide high-quality services to improve customer health while also selling health products that benefit the bottom line.
\end{abstract}

Keywords: Social networking analysis, influence mapping, participatory methods, health communication, visualization, lowand middle-income countries, Kenya

\section{Introduction}

According to UNICEF (2019a), Kenya has a high maternal mortality rate at 342 per 100,000 live births. Per a joint WHO and UNICEF report (2019b), only 59\% of Kenyans have access to basic water services and fewer (29\%), have access to sanitation services. Estimates from a UNICEF study (2017) suggest that $26 \%$ of Kenyan children under age five suffer from nutritional deficiencies and stunting, higher than peer countries such as Ghana and Mauritania.

Online communities provide opportunities to reach specific groups with targeted behavior change messages and campaigns (Wakefield, Loken, and Hornik, 2010; Eysenbach, 2007; Wasko and Faraj, 2000). Online communities focused on health capabilities have uncovered ways to bridge health disparities between rural and urban areas (Goh, Gao and Agarwal, 2016).

However, little systematic knowledge is currently available on how to develop, and scale-up effective behavior change programs for digital communities in low-income markets. There is also little information about key guiding principles and best practices that underlie successful digital and online, social networking models.

Digital tools and the ecosystems they belong to hold great promise and potential for addressing deficits in health care delivery networks in Africa. Opportunities for improving networks can be realized with commitment and investment from government actors, in tandem with local public and private stakeholders (Tambo et al, 2016). 
Innovative models for scaling products and services place digital tools at the center of efforts to bring together stakeholders' intellectual capital and knowledge (Presch, 2020).

\section{Micro-retail enterprises in Kenya}

In Kenya, micro-retail establishments known locally as dukas are pervasive in low-income and under-resourced communities, and serve as primary retail outlets for the majority of the population. Dukas capture a substantial portion of the retail market and supply about $80 \%$ of consumer goods in Kenya (TechnoServ, 2019). Thus, dukas are strategically positioned to serve as conduits to underserved segments of the population. According to Nielsen, there are over 166,000 dukas in Kenya (Mwiti, 2018). Only 10 percent of these dukas have received business training (TechnoServ, 2002) and of those in Nairobi, more than half do not record their sales (Waweru, 2018).

The Transformative Market Based Model for Low Income Household Needs (TRANSFORM) Project in Nairobi, Kenya, (led by DFID and Unilever) revolves around two initiatives, UJoin and UAfya (Wright, et al., 2019; Hendrickx, et al., 2018). Both UJoin and UAfya are digital mobile-friendly platforms that provide services to duka owners. Each initiative uses an online community network to facilitate discussion, and improve knowledge and behaviors regarding livelihoods and health. UJoin and UAfya also seek to build on the formal and informal health communications already happening among micro-retailers, their customers, government regulatory bodies, health professionals, and school teachers

Johns Hopkins Center for Communication Programs (CCP) reviewed six initiatives - independent of TRANSFORMthat use online communities to facilitate behavior change to inform a scale-up model. The results of this review identified five key dimensions important to scaling digital programs:

- Competitiveness: Clear understanding of the ecosystem and the levers that create an enabling environment for growth.

- Capacity: Competence and resources required for sustainable diffusion of innovation.

- Capability: The utility and productivity that consumers derive from the platform.

- Communication: Clear articulation and positioning of a compelling value proposition.

- Collaboration: Strategic partnerships that provide holistic solutions.

\subsection{UJoin Digital Platform}

UJoin is a digital platform that aims to increase business capacity and skills, and access to services and discounted products among duka owner in Kenya (Wright, et al., 2019). Duka owners who register with UJoin have direct access to tools they need to improve their business management skills and to expand their business. The platform, had about 3,000 registered members at the time of the survey. Components of the platform include a duka academy (with courses on financial and credit management, pricing and promotion, record keeping, and business planning), information and links to business support services such as credit and lending institutions and wholesalers, online mentoring and peer-to-peer networking, and a loyalty rewards scheme (UJoin 2019).

\subsection{UAfya Digital Platform}

UAfya is a digital program that focuses on young expectant and new mothers, and women interested in family and maternal health topics. The platform had about 1,500 registered members at the time of the survey. UAfya aims to improve nutrition and hygiene knowledge and behaviors among new and young mothers in Kenya. The need for this is supported by maternal and neonatal data from Kenya.

Dukas help community members develop knowledge about items that can be purchased locally including nutrition supplements and snacks for infants, toddlers, and children, and personal and feminine hygiene products such as deodorant and soap. They also can provide nutritional advice regarding foods they sell for infants, toddlers, children, and reinforce the benefits of eating healthy foods (Demmlera, Ecker, and Qaim, 2018).

Scaling up initiatives like UJoin and UAfya to increase the reach of information and services among dukas requires understanding of the duka community and its networks. Successful program scale-up also includes strategies to support the needs of a larger and more diverse audience. However, there is little information about 
the needs of duka owners beyond skills related to management. More information is needed about their trusted support systems, collaborative networks, information-seeking behaviors, relationships with patrons and each other. This information can be used to inform scale-up and develop strategic interventions that support duka owners personally as well as professionally.

\subsection{Net-Map}

A systematic and participatory tool known as Net-Map (Campbell, et al., 2014), developed by Eva Schiffer, was used to explore and understand potential frameworks for establishing digital-based community-driven partnerships with the private sector for health promotion through behavior change. The Net-Map approach is used to help individuals and groups clarify their view of a situation (including networks and power structures), foster discussion, and develop a strategic approach to their networking activities. It allows groups to visualize key channels and consumer influences. Net-Map has been used in health settings in many low- and middleincome countries. Net-Map has contributed to a better understanding of knowledge exchange among family planning and reproductive health organizations in Ethiopia (Harlan, Sullivan, and Hailegiorgis, 2013.), mobile phone interventions for community workers in Malawi, (Campbell, et al., 2014), and young child feeding policy in Pakistan (Mahmood, et al., 2017).

Th Net-Map activity aimed to provide a deeper understanding of the communication paths and challenges to effectively scale up the diffusion of healthy behaviors for the UAfya and UJoin initiatives. It seeks to understand how to strengthen government involvement in developing the micro-retailers to expand their circle of influence beyond business and become involved in other sectors (health, agriculture, education). It also seeks to understand how to decouple the micro-retailers from foreign aid and create local sustainability and ownership of healthy communities. This means fostering government roles in connecting micro-retailers to develop formal mechanisms for acquiring knowledge from health professionals and educators, and goods from local farmers.

When supported appropriately, duka owners may be in a position to reinforce community behaviors to improve infant care and maternal health by supplementing and promoting messages with business customers, that they receive from health educators and other authoritative health professionals.

\section{Methodology}

The study used qualitative methods, specifically net mapping techniques, to identify and explore the influence of community social actors on health discussions among dukas with retail shops located in two informal settlements, Kibera and Kawangware, in Nairobi, Kenya. Net-mapping was used to develop a visual representation of linkages in the social network of dukas in the study communities.

Investigators developed the specific method, including lines of inquiry, by incorporating the rich body of case study research. This included asking participants to describe the current context through narrative, and speculate on what the future may look like when certain actions are carried out (Yin, 2014; Massaro, Dumay, and Bagnoli, 2019).

\subsection{Study Population}

The study target population was adult (18 years and older) male and female managers of dukas registered with UJoin, and adult (18 years and older) females registered with UAfya online platforms.

\subsection{Sample Selection}

UJoin and UAfya community coordinators assisted with the identification of potential participants. Eligibility criteria for inclusion in the study included managing a duka, being registered with UJoin or UAfya, residence in Kibera or Kawangware for at least 12 months, being 18 years of age or older, and providing voluntary informed consent. In addition to eligibility criteria, a purposeful sample was selected to increase variability and likelihood of representation of diverse backgrounds, perspectives, and experiences within the sample. Sampling criteria also included registrants who: placed within the top $15 \%$ and bottom $15 \%$ of visits to the digital platforms, had signed up the most customers to their loyalty club, had redeemed the most achievements and trophy badges, had completed the most e-learning courses on the site, or had asked for health-related information about products through the platforms. 


\subsection{Sampling}

Four mapping activities, two in Kibera and two in Kawangware, were designed. At each site, one workshop included registered UAfya members and the second included registered UJoin members.

\subsection{Data Collection Tools:}

The main net-map questions of interest were:

- UAfya: Who influences knowledge exchange related to healthy behaviors within the communities of shoppers?

- UJoin: Who influences perceptions among the shopkeepers about their roles in promoting healthy behaviors?

\subsection{Net-Map Process}

The map was constructed in phases. First, working in groups, participants used an open card sort activity to identify actors (influencers) and link types (relationships). Next, participants were re-grouped by age (UAfya) and the number of years managing a duka (UJoin). These groups then were guided by the facilitators to create a map depicting the following information and drawing these on flip-chart paper:

1. The actors influencing the question.

2. The types of links connecting the actors.

3. The strength of each linkage on a three-point scale with ' 1 ' representing a weak link, ' 2 ' a regular link, and ' 3 ' a strong link.

4. The influence level of each actor on an eight-point scale with ' 1 ' representing a low level of influence and ' 8 ' representing a high level of influence. This scale range was determined from influence towers during the pre-test.

5. Whether the actors were aligned with the question as it relates to the overall TRANSFORM goals on a three-point scale (negative, neutral, positive).

Next, facilitators guided participants through a visual analysis of the completed map. First, participants provided their intuitive reactions to what they were seeing on the map, and second, through guiding questions about individual actors and cliques on the map. The guiding questions assessed betweenness centrality, a measure of how often an actor linked others who were not directly linked, and closeness centrality, a measure of the number of steps from one actor to all other actors in the network. Plurality refers to the number of votes cast for actors who receive more than any others but does not receive an absolute majority.

Lastly, the groups representing the two platforms reconvened to compare their maps. Additional discussion among the participants provided insightful and explanatory detail about the differences and similarities in the maps from different groups and locations.

A pre-test of the Net-Map process was completed with 15 UJoin and UAfya project managers in Nairobi. The activity enabled a review of the mapping procedures, guiding questions, potential links, and actor types that were developed using pre-existing knowledge of the local context. After-action review of the pre-test results was conducted to refine plans for data collection.

\subsection{Ethics and Protections}

The study protocol was reviewed by the Johns Hopkins University School of Public Health Institutional Review Board, and designated not-human subjects research under protocol \#9786. Procedures to protect participants' rights and information were included in the data collection and management process. No names or personal and private information was collected in the notes or maps, and the data analyzed were de-identified. No data was collected before obtaining informed consent from all participants.

\subsection{Permissions}

Local permissions for community entry and to conduct the study were obtained from community leaders at each site, prior to approaching any potential participants.

\subsection{Data collection}

The data were collected at community centers in Kibera and Kawangware over a period of four days in September 2019. The net mapping activity was facilitated by program officers from Johns Hopkins CCP and 
community coordinators from the UJoin and UAfya programs. Notetakers captured the discussions among the group as they constructed the net-map.

\subsection{Analysis}

The data collected from the maps and notes were inputted into proprietary software, (D)atamuse (2020). The maps were analyzed quantitatively for closeness and betweenness. Other quantitative measures summarizing the influence of actors examined the relationship between the number of connections and the degree of alignment with TRANSFORM goals. The analysis included isolation (or disaggregation) of specific portions of maps for separate analysis, such as all links of a certain type, or all links to a certain actor, to generate information about a specific influence or actor.

\section{Findings}

Eight net-maps were constructed by shopkeepers and women interested in family health. They were stratified by groups based on location and digital platform. Each map was constructed by an average of 9.5 individuals for a total of 76 participants. The average time to complete one map was seven hours. Table 1 below summarizes the key terms for interpreting the net-map.

Table 1: Summary of legends and symbols used to create the Net-Map visual

\begin{tabular}{|l|l|}
\hline Information summarized & Graphical representation \\
\hline Actors & Depicted by circles \\
\hline Types of actors & Indicated by the color of each circle \\
\hline Influence of actor & Depicted by the size of the circle (larger = more influence) \\
\hline Linkages & Depicted by arrows \\
\hline Types of linkages & Indicated by the color of each arrow \\
\hline Strength of the relationship & Suggested by the thickness of the arrow (thicker = stronger relationship) \\
\hline
\end{tabular}

For each of the eight maps shared in this article, a corresponding influence-connection matrix is included. On these matrices, points reflecting more than one actor (i.e., when the number next to the point is greater than $1)$, the color of the point may not reflect the type of all actors at that point.

\subsection{UAfya Results}

\subsubsection{Actor Types}

A comparison of the discussions associated with the creation of the maps produced by Kibera and Kawangware. UAfya members show that three actor types are the most important: local government, family, and friends, and the media. Overall, actor types identified were similar between the study communities. These are summarized in Table 2 below.

Table 2: Actor types identified in Kibera and Kawangware

\begin{tabular}{|l|l|}
\hline Kibera & Kawangware \\
\hline Family and Friends & Family and Friends \\
\hline Government & Government \\
\hline Media & Media \\
\hline Social communities/CBO (community-based organizations) /NGO & Community Institutions \\
\hline Business Partners & Companies \\
\hline
\end{tabular}




\begin{tabular}{|l|l|}
\hline Kibera & Kawangware \\
\hline Health Practitioners & NGOs \\
\hline
\end{tabular}

Key differences were evident for labels for business partners versus companies, and social communities/CBOs/NGOs versus community institutions. In addition, actor types with different scopes were health practitioners in Kibera and promoters/advertisers in Kawangware.

\subsubsection{Link Types}

A comparison of the discussions associated with the creation of the maps by UAfya members shows that the two most important link types are conflict, and collaboration/partnership.

Overall, link types identified were similar between the study communities. These are summarized in table three below.

Table 3: Link types identified in Kibera and Kawangware

\begin{tabular}{|l|l|}
\hline Kibera & Kawangware \\
\hline Information Sharing & Communication \\
\hline Collaborating and Partnering & Partnership, Collaboration, Funding \\
\hline Trading and Services & Trading \\
\hline Conflict & Conflict \\
\hline & Providing Services \\
\hline
\end{tabular}

Key differences were evident for labels for information sharing versus communication, and trading and services formed one link in Kibera while in Kawangware, these two links were separated.

Maps generated for actor and link types derived from sub-groups of the sample - younger versus older participant groups - are presented below for each of the two study locations.

\subsection{Kibera: Older Participants}

In Figure 1 below, results show that a total of 25 actors or groups of actors were identified by older participants. The plurality of these actors were business partners (6), and government (5) actors.
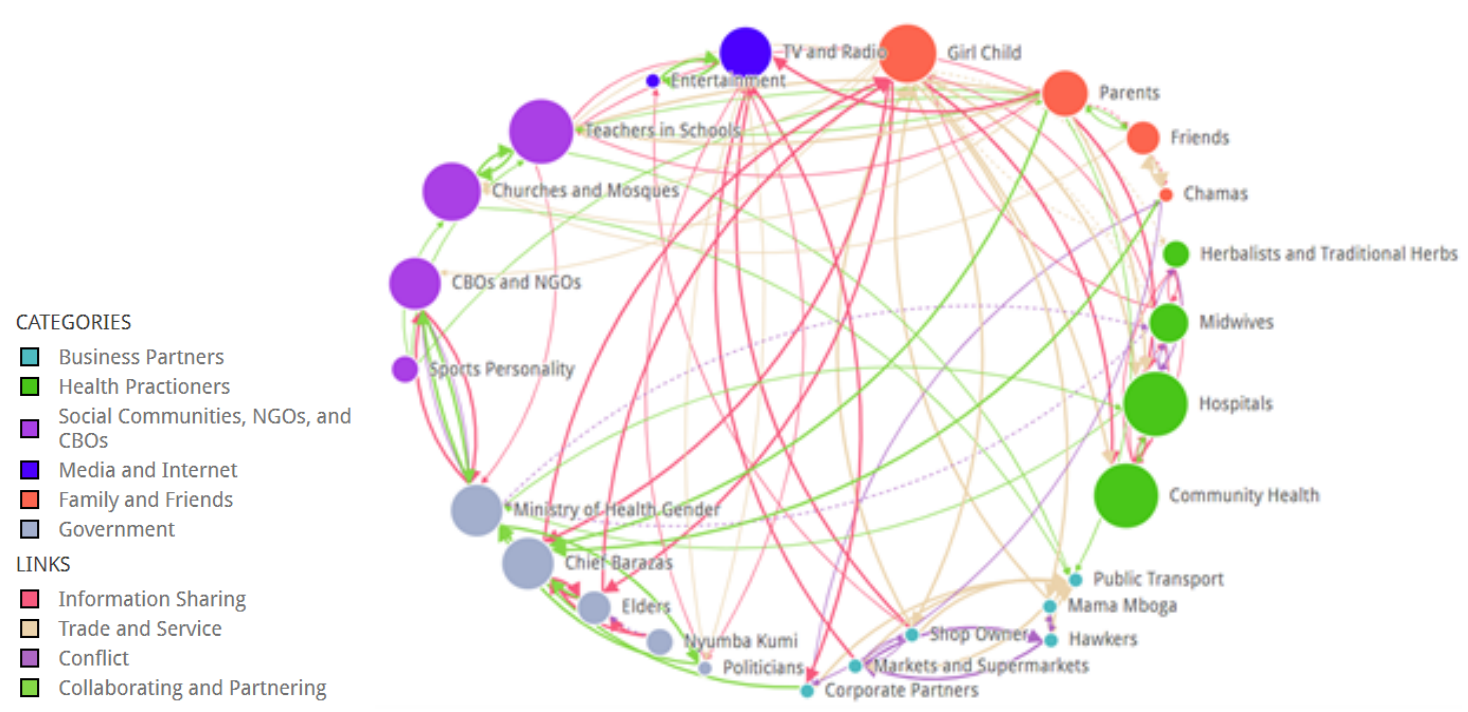

Figure 1: Net-Map of actors and linkages for older participants from Kibera 


\subsubsection{Actors}

The map also showed that among all actors, teachers in schools, community health actors, and hospitals had the highest influence rating (eight on a scale of $0-8$ ). In this and subsequent maps, Actors that are unique to Kenya include Mama Mbogas, informal vegetable sellers, and Nyumba Kumi, a neighborhood watch organization centered on groups of 10 houses. The girl child is defined as girls of school age.

\subsubsection{Linkages between Actors}

A total of 108 links were identified by older participants, including information sharing (35) and trade and services (30). According to this group's map, 47 links were defined as strong, 53 were normal, and eight were weak.

\subsubsection{Influence and connections}

In Figure 2 below, a matrix compares the number of connections for each actor ( $\mathrm{X}$-axis) with their influence ( $\mathrm{Y}$ axis). Results showed that friends and family were perceived to have higher influence and more connections (top right quadrant) compared to business partners and government actors with fewer connections and less influence (bottom left quadrant). Teachers in particular (identified with a green square), had a high level of influence and a high number of connections. The girl child, (identified by the red dot furthest to the right) also had notable influence and was highly connected among all the actors. Social communities/NGOs/CBOs were classified as having high influence but were poorly connected. The least influential and connected actors were the government and especially business partners and media and the internet.

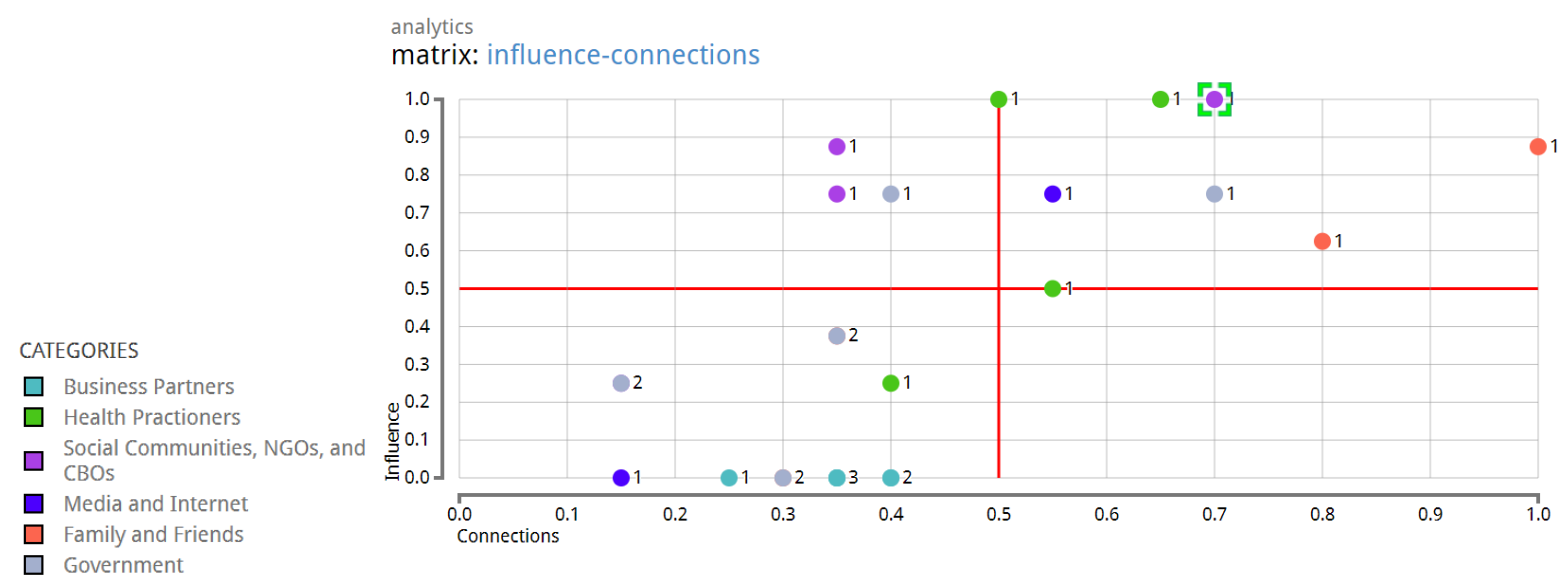

Figure 2: Influence-Connection matrix for older participants from Kibera

The key findings for social network metrics, closeness and betweenness, are as follows:

- Closeness: The girl child was the most closely linked to all actors in the network. This network was closeknit with many close connections across actors. Relative to the girl child, all other actors shared a similar and lower closeness factor.

- Betweenness: the girl child, public transport, television and radio, parents, and chief barazas (representatives of the local chief) made key intermediary connections by linking other actors who did not have relationships with one another.

\subsection{Kibera: Younger Participants}

In Figure 3 below, a complete Net-Map depicting relevant actors and linkages is shown for the group of younger (less than 28 years of age) participants from Kibera. A total of 25 actors or groups of actors were identified by younger participants and the majority of them were business partners (7) and health practitioners (5). 


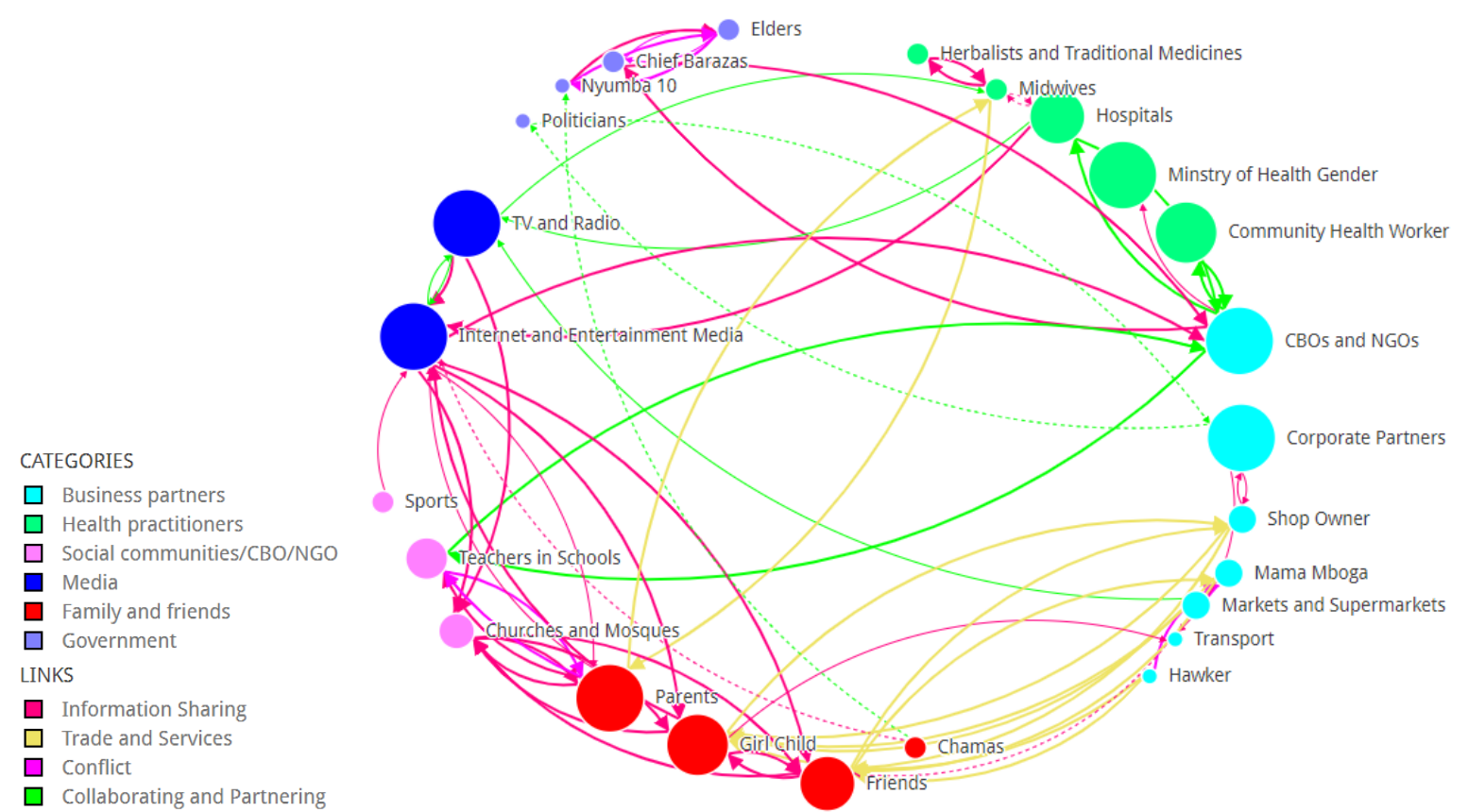

Figure 3: Net-Map of actors and linkages for younger participants from Kibera

\subsubsection{Actors}

The map also showed that among all actors, corporate partners, CBOs and NGOs, MOH's gender unit, television and radio, internet and entertainment media, and parents had the highest influence rating of eight on a scale of $0-8$.

\subsubsection{Linkages between Actors}

A total of 67 links were identified by the young participants from Kibera, including information sharing (34) and collaborating and partnering (14). 45 of the links were defined as strong, 15 were normal, and seven were weak.

\subsubsection{Influence and connections}

In Figure 4 below, a matrix compares the number of connections of each actor (X-axis) with their influence ( $Y$ axis). Among younger participants from Kibera, friends and family actors had higher influence and higher connections while business partners and government actors had fewer connections and less influence. Teachers, identified with a green square, were perceived to have a moderate level of influence but a low number of connections. The internet and entertainment media (blue dot in the extreme top right) had the strongest influence and connection compared to other actors. Younger participants rated substantially more actors with fewer connections and less influence than the older participant group, and these were primarily business partners and government. Health practitioners were perceived to be influential but lacked connections while social communities had low influence and variable results for connections.

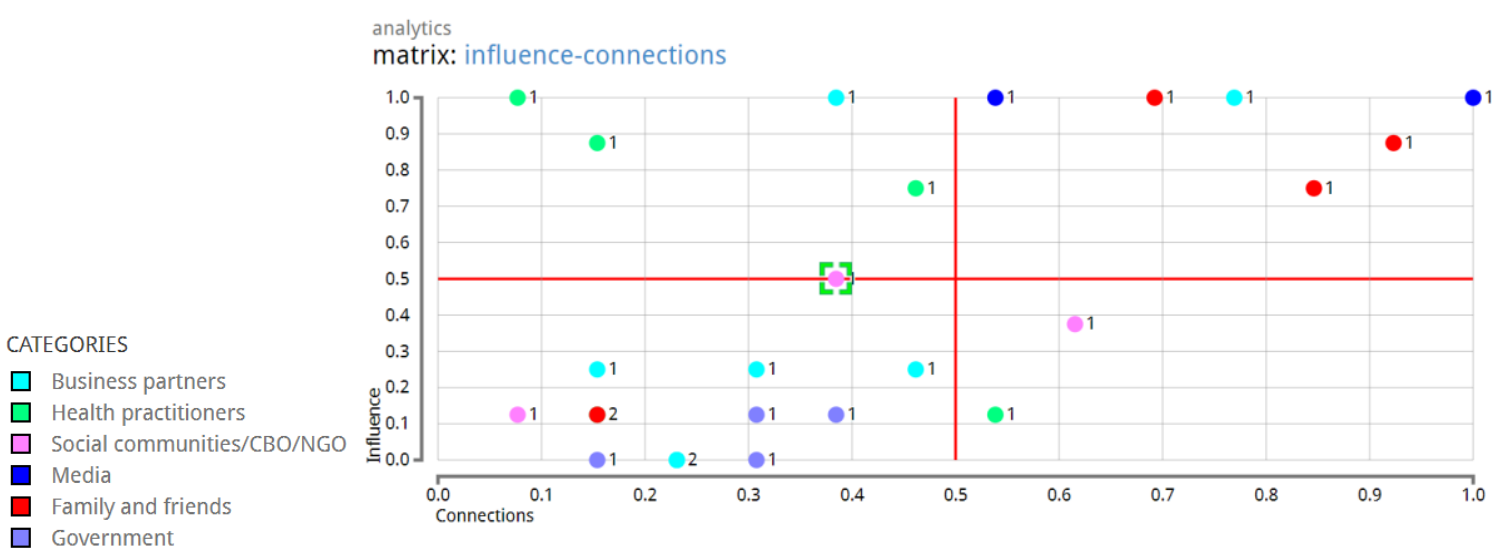

Figure 4: Influence-Connection matrix for younger participants from Kibera 
Social network analysis metrics: Closeness and Betweenness

- Closeness: The girl child, CBOs and NGOs, hospitals, churches and mosques, TV and radio, internet and entertainment media, chamas, parents, friends, and elders were most closely linked to all actors in the network. Relative to the actors listed above, the other actors shared a similar and lower closeness factor.

- Betweenness: the girl child, CBOs and NGOs, and internet and entertainment media had connecting roles and linked other actors but did not necessarily have relationships with one another. Hawkers, herbalists and traditional medicine vendors, the Ministry of Health/Gender unit, community health workers, sports figures, and politicians had the lowest scores for betweenness.

\subsection{Kawangware: Older Participants}

In Figure 5 below, a complete Net-Map depicting relevant actors and linkages is shown for older ( 30 years and older) participants from Kawangware. Older participants identified 31 actor types the majority of whom were community institutions (8), companies (6), or NGOs (6). Small and medium-sized businesses have been anonymized.
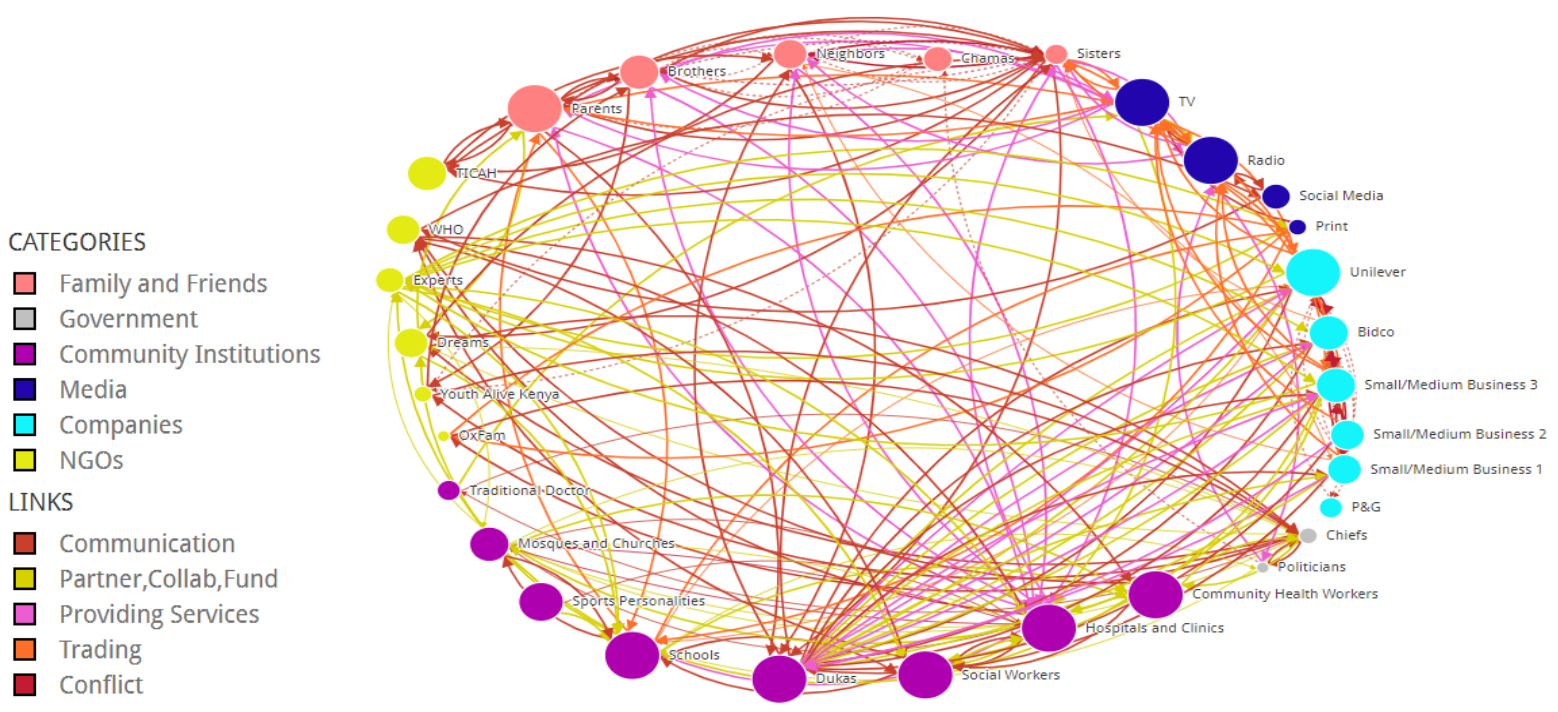

Figure 5: Net-Map of actors and linkages for older participants from Kawangware

\subsubsection{Actors}

The map showed that schools, hospitals and clinics, social workers, dukas, community health workers, television, radio, parents, and Unilever Company had the highest influence rating of eight on a scale of $0-8$, among all the actors.

\subsubsection{Linkages between Actors}

Older participants identified substantially more linkages than younger participants. Specifically, a total of 206 links were identified including communication (86) and partnership, collaboration, and funding (49). According to this group's map, 157 links were defined as strong, 23 were normal, and 26 were weak.

\subsubsection{Influence and connections}

In Figure 6 below, a matrix compares the number of connections of each actor (X-axis) with their influence ( $Y$ axis). The results show that older participants from Kawangware perceived that companies, community institutions, media, and friends and family, had higher influence and more high connections while NGOs and government actors had fewer connections and less influence. Schools, in particular, identified with a green square, had a high level of influence and a high number of connections, as did television, hospitals and clinics, and dukas respectively. 


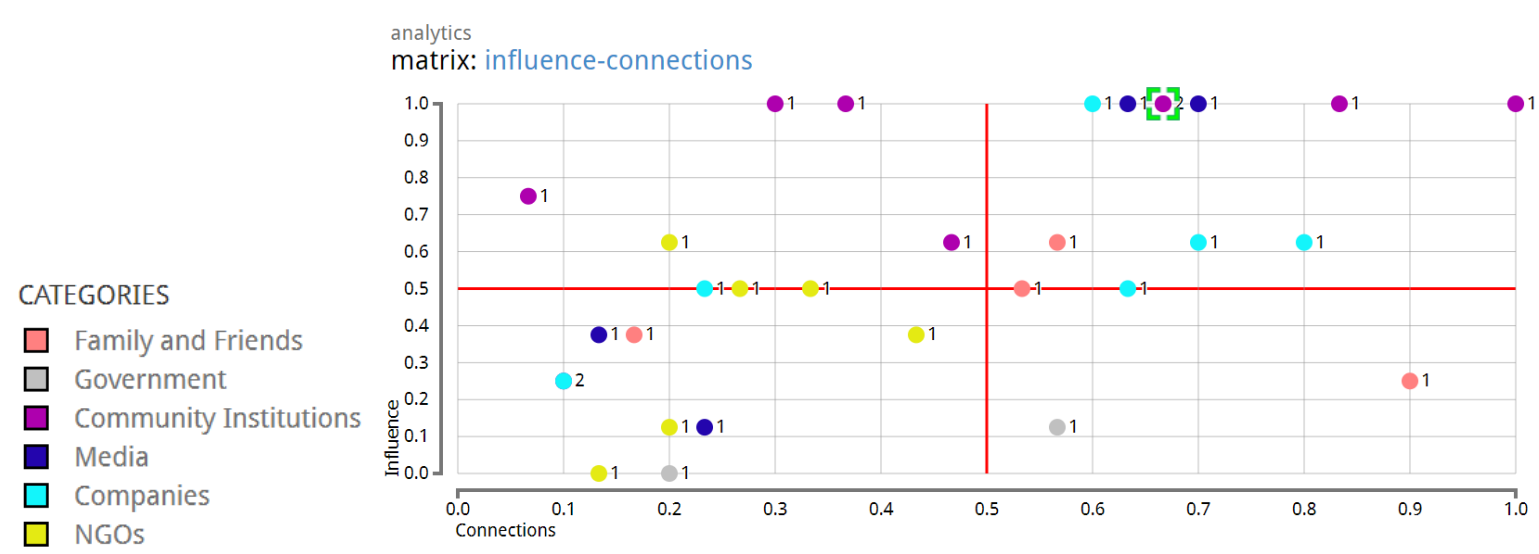

Figure 6: Influence-Connection matrix for older participants from Kawangware

Social network analysis metrics: Closeness and Betweenness

- Closeness: Twenty actors shared the highest status pertaining to relative proximity to all actors in the network. Schools, radio, TV, Unilever, brothers, Bidco, and Small/Medium Business 3 were among these 20 actors. The remaining 11 actors shared a similar and lower closeness factor.

- Betweenness: Schools, hospitals and clinics, and television had the most connecting roles by linking other actors that did not necessarily have relationships with one another. Chamas (women's collectives), sports personalities, social media, Proctor and Gamble, the Trust For Indigenous Culture And Health (TICAH), and OxFam shared the lowest betweenness factor.

\subsection{Kawangware: Younger Participants}

Figure 7 below is a complete Net-Map depicting relevant actors and linkages for younger participants (younger than 30 years) from Kawangware. A total of 30 actors were identified by younger participants, and the majority of these actors were community institutions (8) and companies (6). Small and medium-sized businesses have been anonymized.
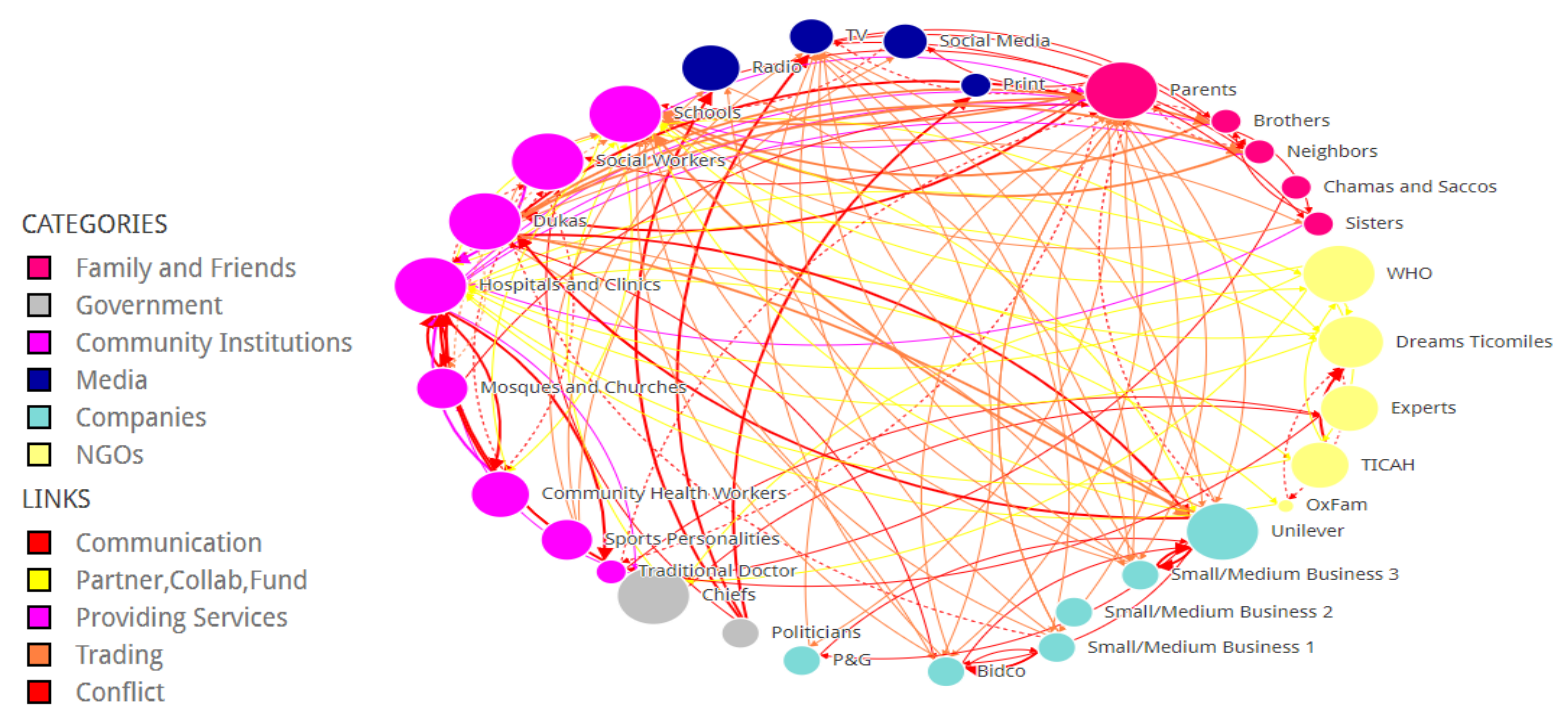

Figure 7: Net-Map of actors and linkages for younger participants from Kawangware

\subsubsection{Actors}

The results showed that schools, parents, chiefs, hospitals and clinics, social workers, Unilever company, the World Health Organization, and dukas had the highest influence rating of eight on a scale of 0-8.

\subsubsection{Linkages between Actors}

A total of 128 links were identified by younger participants from Kawangware including trading (42) and conflict (38). According to this group's map, 28 links were defined as strong, 84 were normal and 16 were weak. 


\subsubsection{Influence and connections}

Figure 8 below compares the number of connections of each actor (X-axis) with their influence (Y-axis). Few actors in the community institution category had high influence and high connections while most companies had fewer connections and less influence. Community institutions, especially schools (identified with a green square) had a high level of influence and a high number of connections, as did hospitals and clinics, and parents. Parents (red dot in the top right corner) were perceived to have the highest number of connections and influence. However, younger participants identified more actors with high influence but limited connections, such as NGOs, a result that is similar to that of the older participants. Unlike the older participants, the younger participants perceived companies and the media as having less influence and connections, however, this may refer to media channels for business rather than for social and entertainment purposes.
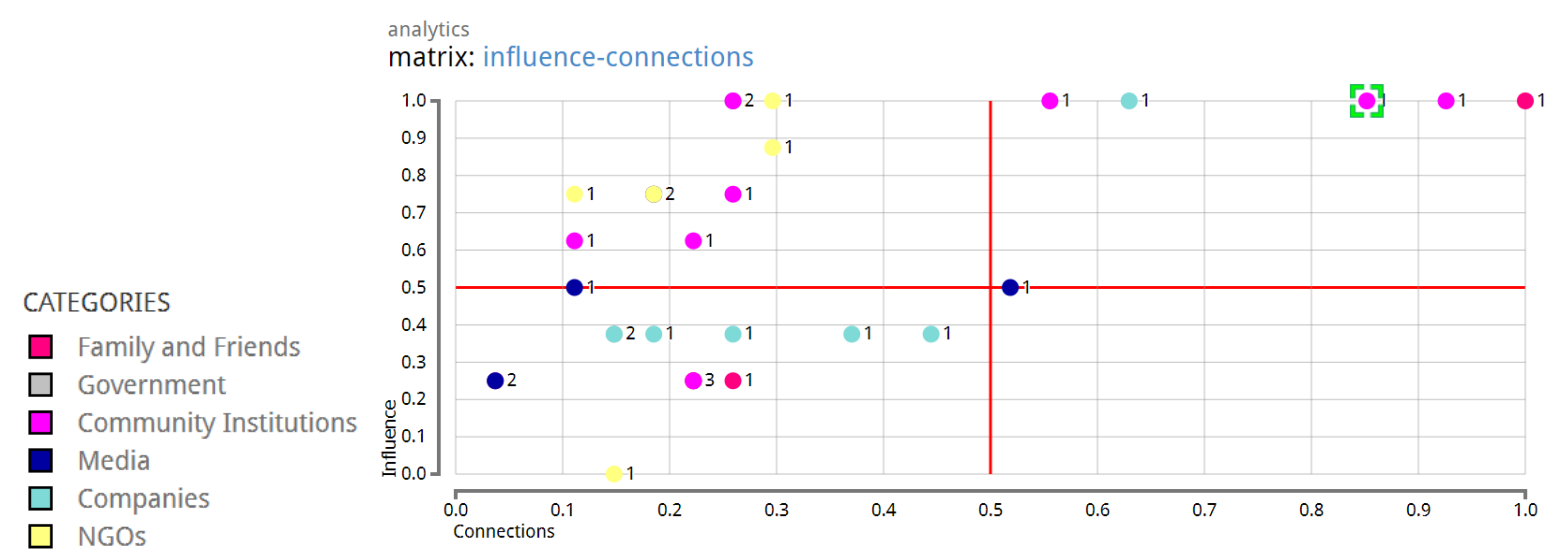

Figure 8: Influence-Connection matrix for younger participants from Kawangware

Social network analysis metrics: Closeness and Betweenness

- Closeness: 21 actors shared the highest status pertaining to relative proximity to all actors in the network. Schools, hospitals and clinics, Unilever, dukas were among these 21 actors. The remaining 9 actors shared a similar and lower closeness factor.

- Betweenness: Schools, hospitals and clinics, parents, chiefs, television, and community health workers, had connecting roles by linking other actors that did not necessarily have relationships with one another. Chamas (women's cooperatives) and Saccos (credit cooperatives), print media, Small/Medium Business 1, Small/Medium Business 2, the Trust For Indigenous Culture And Health (TICAH), OxFam, and health experts shared the lowest betweenness factor.

Table 4: Summary of Net-Map results for actors, connections, perceived influence, and connectedness, by study site

\begin{tabular}{|c|c|c|c|c|}
\hline \multicolumn{5}{|l|}{ UAfya } \\
\hline & \multicolumn{2}{|l|}{ Kibera } & \multicolumn{2}{|l|}{ Kawangware } \\
\hline & Younger & Older & Younger & Older \\
\hline$\#$ Actors & 25 & 25 & 30 & 31 \\
\hline \# Connections & 67 & 108 & 128 & 206 \\
\hline $\begin{array}{l}\text { High Influence and Many } \\
\text { Connections }\end{array}$ & $\begin{array}{l}\text { Family and Friends } \\
\text { Media }\end{array}$ & $\begin{array}{l}\text { Family and } \\
\text { Friends } \\
\text { Health } \\
\text { Practitioners }\end{array}$ & $\begin{array}{l}\text { Community } \\
\text { Institutions } \\
\text { Family and Friends }\end{array}$ & $\begin{array}{l}\text { Companies } \\
\text { Community Institutions } \\
\text { Media } \\
\text { Family and Friends }\end{array}$ \\
\hline $\begin{array}{l}\text { High Influence and Few } \\
\text { Connections }\end{array}$ & Health Practitioners & $\begin{array}{l}\text { Social } \\
\text { Communities } \\
\text { NGOs, CBOs }\end{array}$ & $\begin{array}{l}\text { Community } \\
\text { Institutions } \\
\text { NGOs }\end{array}$ & Community Institutions \\
\hline $\begin{array}{l}\text { Low Influence and Many } \\
\text { Connections }\end{array}$ & $\begin{array}{l}\text { Social Communities } \\
\text { NGOs, CBOs }\end{array}$ & None & None & Government \\
\hline
\end{tabular}




\begin{tabular}{|l|l|l|l|l|}
\hline UAfya & \multicolumn{3}{|l|}{ Kibera } & \multicolumn{3}{l|}{ Kawangware } \\
\hline & Younger & Older & Younger & Older \\
\hline & 25 & 25 & 30 & 31 \\
\hline \# Actors & 67 & 108 & 128 & 206 \\
\hline \# Connections & $\begin{array}{l}\text { Government } \\
\text { Business Partners } \\
\text { Connections }\end{array}$ & $\begin{array}{l}\text { Government } \\
\text { Business Partners }\end{array}$ & Companies & NGOs \\
\hline
\end{tabular}

\subsection{UJoin Participants}

The discussions and maps created by participants that were members of the UJoin digital platform were compared for those residing in Kibera and those in Kawangware.

\subsubsection{Actor Types}

Overall, UJoin participants in Kibera and Kawangware identified similar types of actors in their community. The three most important actor types were local government, business and financial institutions, and customers.

Table 5: Actor types identified in Kibera and Kawangware

\begin{tabular}{|l|l|}
\hline Kibera & Kawangware \\
\hline Customers & Customers \\
\hline Government & Government \\
\hline Financial Institutions & Financial Institutions \\
\hline Shop Owners & Shop Owners, Landlords, Premises, Security \\
\hline Suppliers, Promoters, and Manufacturers & Suppliers \\
\hline Wholesalers & Wholesalers, Hawkers, and Distributors \\
\hline
\end{tabular}

There were few differences in scope regarding how actor groups were defined. Specifically, in Kibera, "wholesalers" were identified as a distinct group, while in Kawangware, the group was broader and included distributors, and hawkers. Conversely, in Kawangware, "suppliers" was a distinct actor type, while in Kibera, it was broadly defined to include manufacturers and promoters. Last, in Kibera, "shop owners" was a distinct link while in Kawangware they were combined with landlords, premises, and security.

\subsubsection{Link Types}

Participating UJoin members identified regulation, and conflict and competition, collaboration and information sharing as key links between actors.

Table 6: Link types identified in Kibera and Kawangware

\begin{tabular}{|l|l|}
\hline Kibera & Kawangware \\
\hline Conflict and Competition & Competition \\
\hline Trading & Stocking \\
\hline Regulation & Regulation and Rules \\
\hline Information Sharing/Price List Checking & Communication \\
\hline Partnership, Collaboration, Support, Facilitation & Discounting and Pricing \\
\hline
\end{tabular}


The other link types were similar but differed in scope or labeling. Specifically, in Kibera, "Information sharing" was combined with "price list checking" compared to "Communication" in Kawangware, and "partnership, collaboration, support, facilitation" was a distinct category in Kibera compared to "discounting/pricing" in Kawangware.

Length of time managing a duka was dichotomized into a short time (less than 6 years) and a long time (6 or more years). Those with less than 6 years of duka management were labeled 'new managers' and those with 6 or more years of duka management were labeled 'experienced managers.' Maps were generated for sub-groups of the sample based on the average number of years the group had managed a duka, for each study site.

\subsection{Kibera: New Managers}

Figure 9 below is a map for participants from Kibera who had managed a duka for a short amount of time. They identified a total of 36 actors.
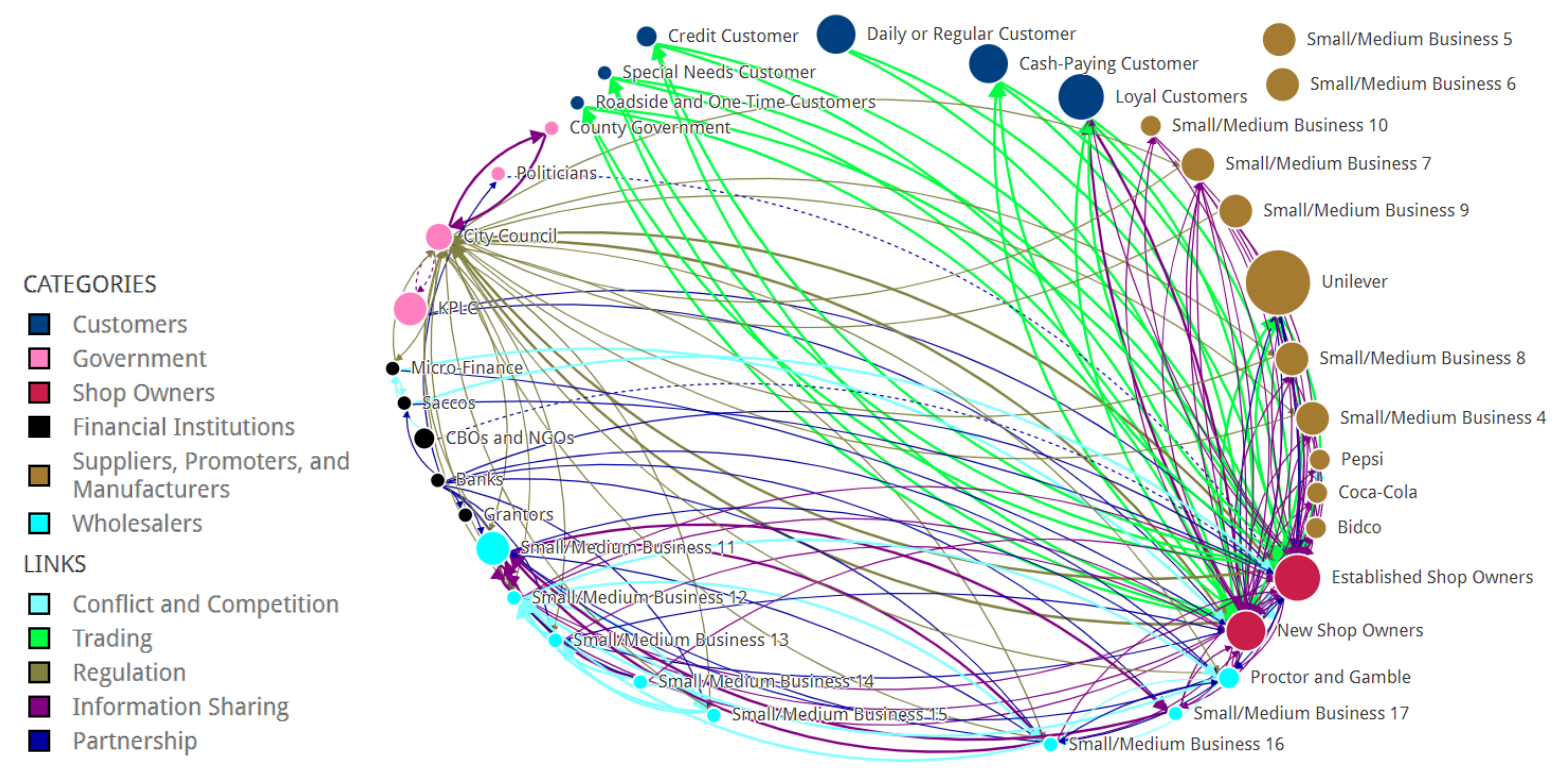

Figure 9: Net-Map of actors and linkages for participants who are new duka managers, from Kibera.

\subsubsection{Actors}

A majority of actors were suppliers, promoters, and manufacturers (11) and wholesalers (8). The map also showed that among all actors, Unilever as a supplier, promoter, and manufacturer, had the highest influence rating of eight on a scale of $0-8$. Small and medium-sized businesses have been anonymized.

\subsubsection{Linkages between Actors}

A total of 172 links were identified by participants who had managed a duka for less than 6 years, including information sharing (67), and regulations and rules (25). Among these, 58 links were defined as strong, 110 were normal, and four were weak.

\subsubsection{Influence and connections}

In Figure 10 below, a matrix compares the number of connections of each actor (X-axis) with their influence (Yaxis). Results show that shop owners were perceived to have high influence and high connections. The red dots on the far right represent new shop owners (bottom), and established shop owners (top), On the other hand, financial institutions, wholesalers, and suppliers, promoters, and manufacturers had few connections and low influence. In this figure the city council, identified with a green square, was classified with a low level of influence and a high number of connections. 

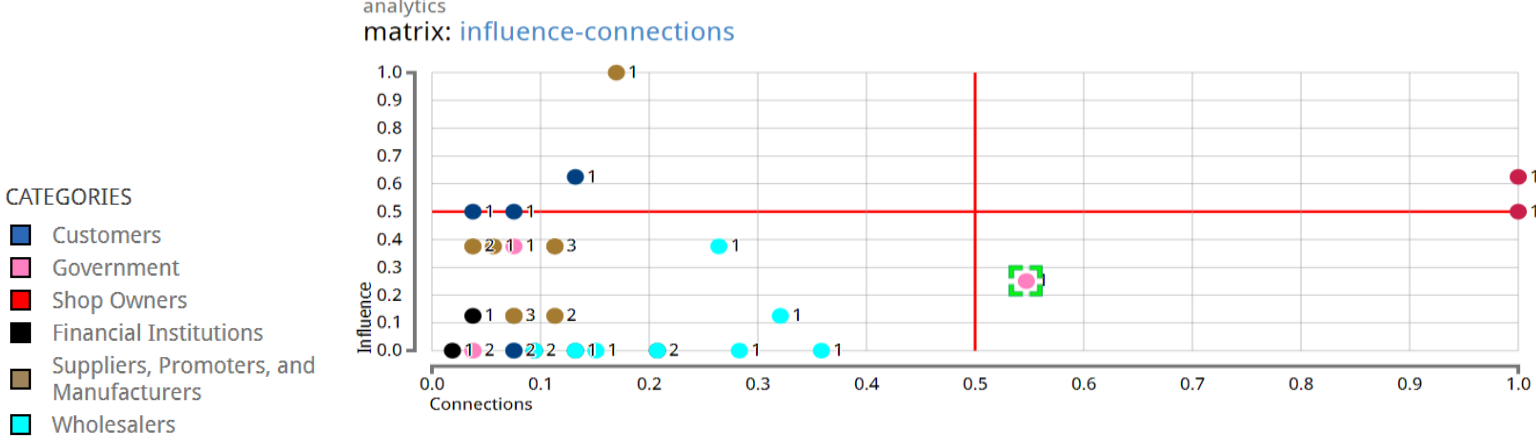

Figure 10: Influence-Connection matrix for participants who are new duka managers, from Kibera

Social network analysis metrics: Closeness and Betweenness

- Closeness: City council, new shop owners, established shop owners, banks, Small/Medium Business 16, Proctor and Gamble, Small/Medium Business 12, and Small/Medium Business 13 were closely linked to all actors in the network. The remaining actors shared the lowest closeness factor.

- Betweenness: City council and new and established shop owners had connecting roles by linking other actors that did not necessarily have relationships with one another. Twenty-six actors shared the lowest betweenness factor.

\subsection{Kibera: Experienced Managers}

The map below shows 37 actors and their linkages identified by new managers from Kibera.

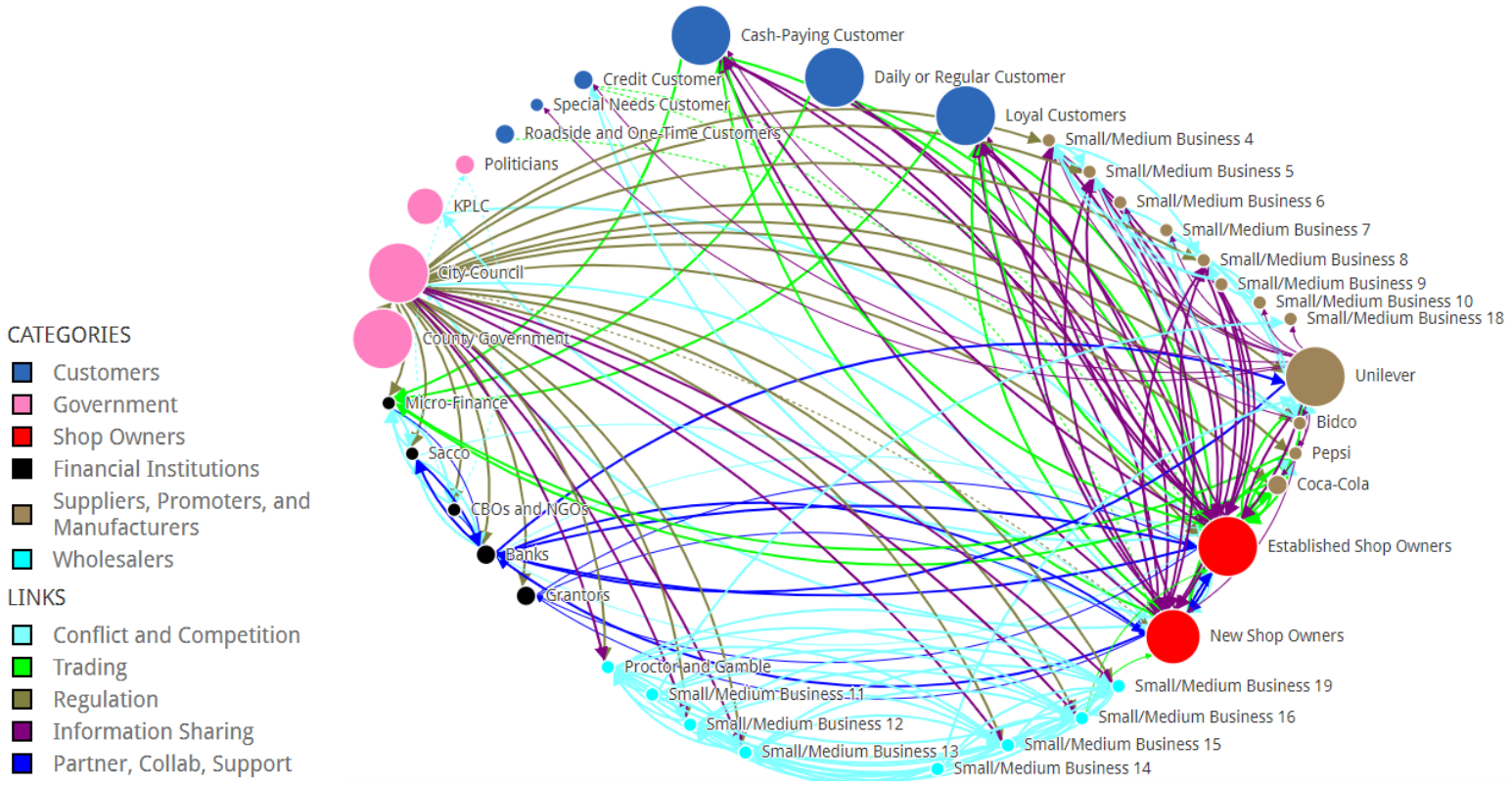

Figure 11: Net-Map of actors and linkages for participants who are experienced duka managers, from Kibera

\subsubsection{Actors}

Actors included suppliers, promoters, and manufacturers (12) and wholesalers (8). According to participants that were experienced managers, seven actors shared the highest influence rating. The city council, county government, cash-paying customers, daily customers, loyal customers, established shop owners, and Unilever had the highest influence rating of eight on a scale of $0-8$. Small and medium-sized businesses have been anonymized.

\subsubsection{Linkages between Actors}

A total of 191 links were identified by participants who were experienced duka managers, including conflict and competition (80) and information sharing (47). Of these, 156 links were defined as strong, 27 were normal, and eight were weak. 


\subsubsection{Influence and connections}

Figure 12 below compares the number of connections of each actor (X-axis) with their influence (Y-axis). Results show that shop owners had high influence and more connections while suppliers, promoters, and manufacturers, and wholesalers had fewer connections and less influence (bottom left quadrant). In this figure, the city council, identified with a green square, has a high level of influence and a high level of connections. The red dots on the far right represents new shop owners (bottom) and established shop owners (top).

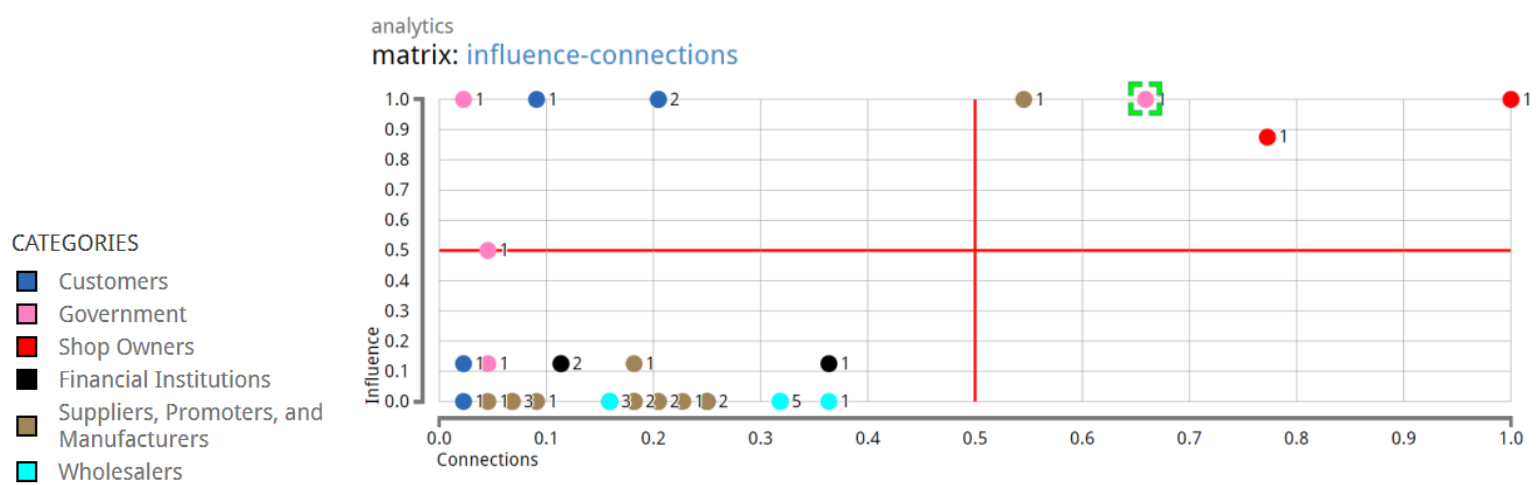

Figure 12: Influence-Connection matrix for participants who are experienced duka managers, from Kibera

Social network analysis metrics: Closeness and Betweenness

- Closeness: City Council, banks, and Unilever were most closely linked to all actors in the network. This network was close-knit with many close connections across actors. The remaining actors shared the lowest closeness factor.

- $\quad$ Betweenness: city council, established shop owners, new shop owners, and Unilever played the most important connecting roles by linking other actors that may not necessarily have relationships with one another. Twenty-one actors shared the lowest betweenness factor.

\subsection{Kawangware: Experienced Managers}

Figure 13 below shows a total of 37 actors and their linkages identified by experienced duka managers from Kawangware.
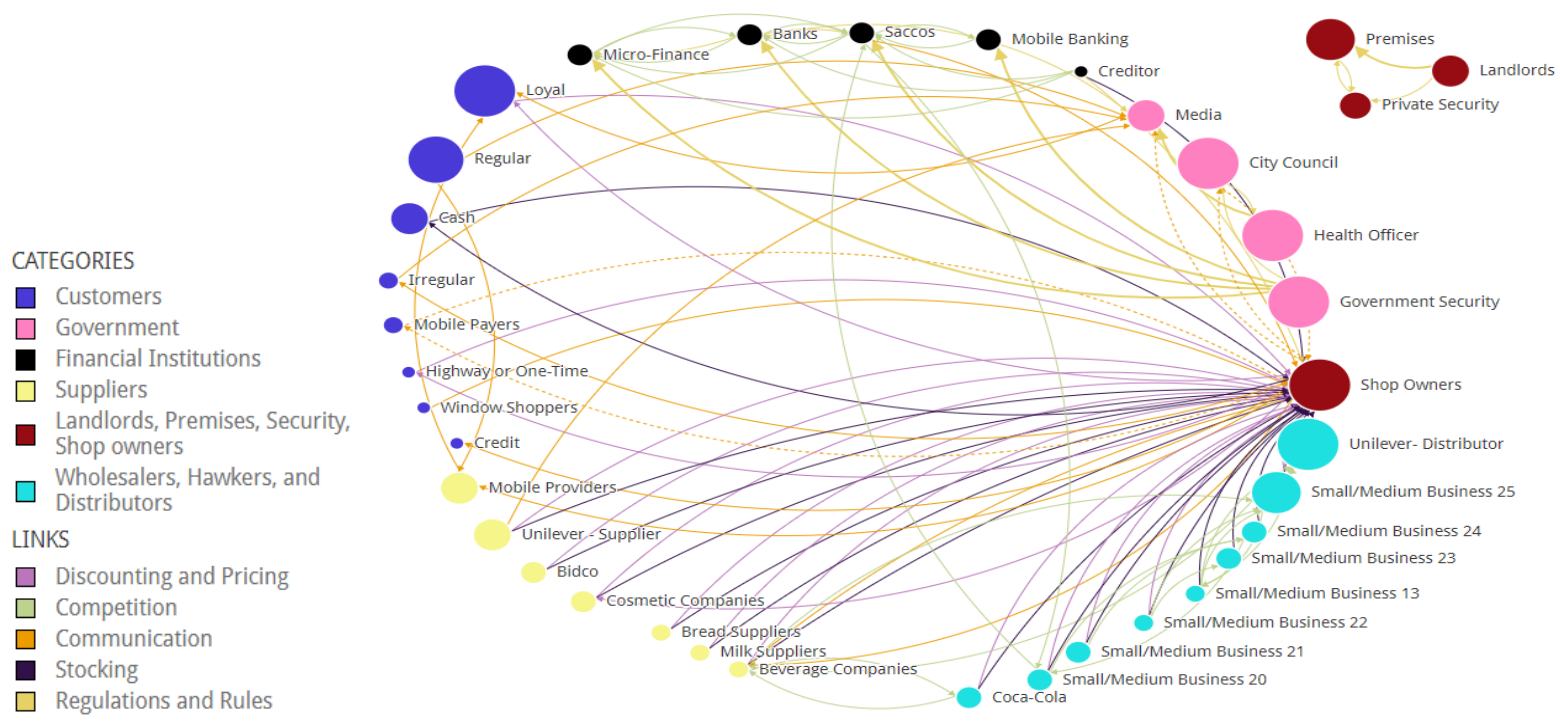

Figure 13: Net-Map of actors and linkages for participants who are experienced duka managers, from Kawangware

\subsubsection{Actors}

A majority were wholesalers, hawkers, and distributors (9), customers (8), and suppliers (7). Among all the actors, the city council, Unilever as a distributor, loyal customers, shop owners, government security, and health 
officers, had the highest influence rating of eight on a scale of 0-8. Small and medium-sized businesses have been anonymized.

\subsubsection{Linkages between Actors}

A total of 95 links were identified by participants who were experienced duka managers, including competition (28), communication (18), and stocking (18). Six links were defined as strong while 84, normal, and five were weak. A clique, comprising actors responsible for securing neighborhood premises, private security, and landlords are influential in promoting the health role of duka managers but are not connected to the larger network of actors.

\subsubsection{Influence and connections}

Figure 14 below compares the number of connections for each actor (X-axis) with their influence (Y-axis). Results show that experienced managers from Kawangware perceived almost all actors to have few connections: Shop owners - the Net-Map participant's peers - were the only actors classified as having high influence and high connections. Most wholesalers, hawkers, distributors, and all financial institutions had fewer connections and less influence. The city council, identified with a green square, had a high level of influence but a few connections. The two dots to the right of the city council represent Unilever (light blue) and shop owners (dark red). Experienced managers from Kawangware did not classify any actors as highly connected with low influence.
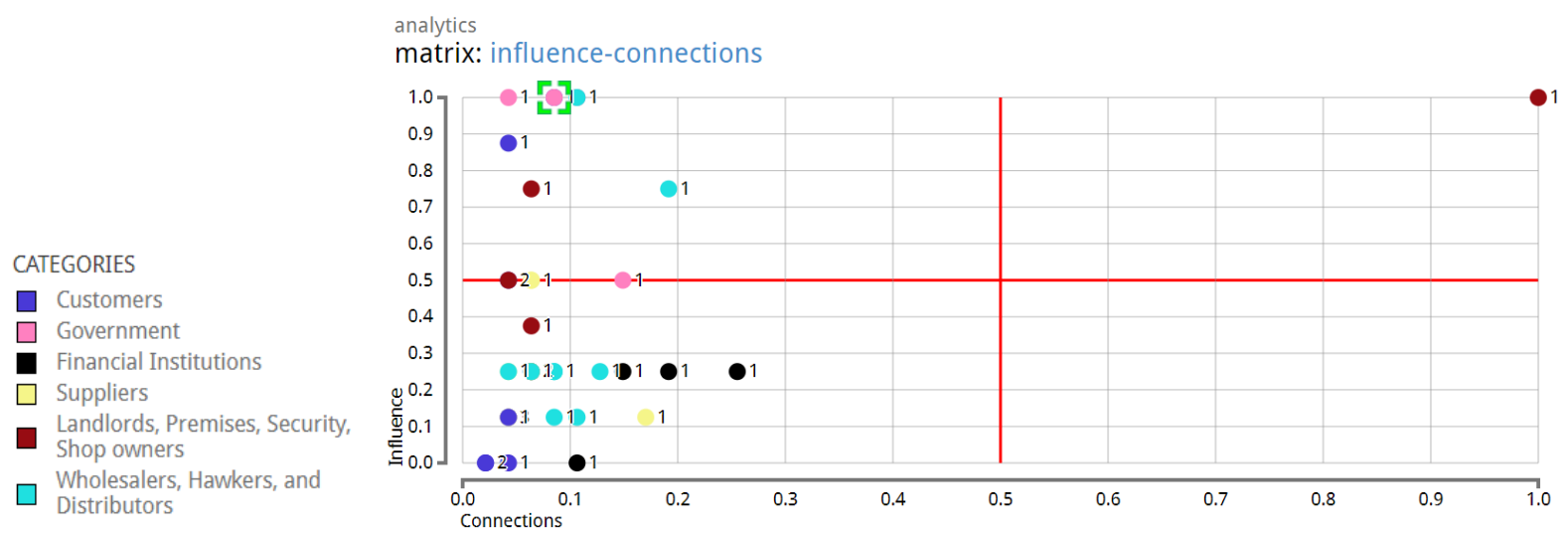

Figure 14: Influence-Connection matrix for participants who are experienced duka managers, from Kawangware

Social network analysis metrics: Closeness and Betweenness

- Closeness: City council, loyal customers, media, SACCOs, creditors, shop owners, and Small/Medium Business (20) were closely linked to all actors in the network. Relative to those listed above, the other actors shared a similar and lower closeness factor.

- Betweenness: Shop owners and SACCO had connecting roles by linking other actors that did not necessarily have relationships with one another.

\subsection{Kawangware: New Managers}

Figure 15 below shows 38 actors and linkages identified by new managers of a duka, from Kawangware. 


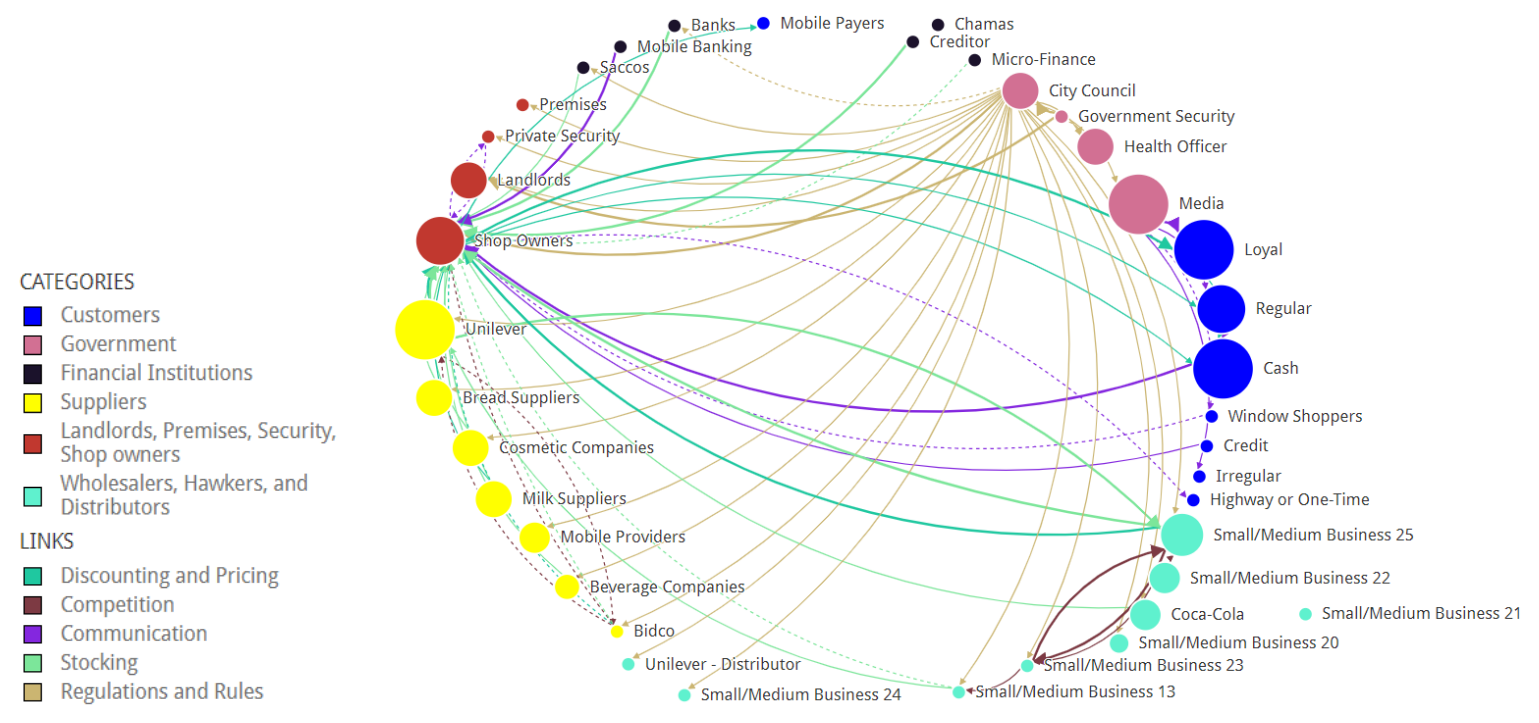

Figure 15: Net-Map of actors and linkages for participants who are new managers of a duka, from Kawangware

\subsubsection{Actors}

A majority of actors were wholesalers, hawkers, and distributors (9), customers (8), and suppliers (7). Among all the actors, the city council, cash customers, loyal customers, media, and Unilever as a supplier had the highest influence rating of eight on a scale of 0-8. Small and medium-sized businesses have been anonymized.

\subsubsection{Linkages between Actors}

A total of 64 links were identified by new managers from Kawangware, including regulation and rules (24) and stocking (15). Among these, 16 links were strong, 33 were normal, and 15 were weak.

\subsubsection{Influence and connections}

Figure 16 below compares the number of connections of each actor (X-axis) with their influence (Y-axis). Results show that shop owners (red dot in the right quadrant) had high influence and more connections, while suppliers, wholesalers, hawkers, and distributors had fewer connections and less influence. The city council, identified with a green square, had a moderate level of influence and a high number of connections.
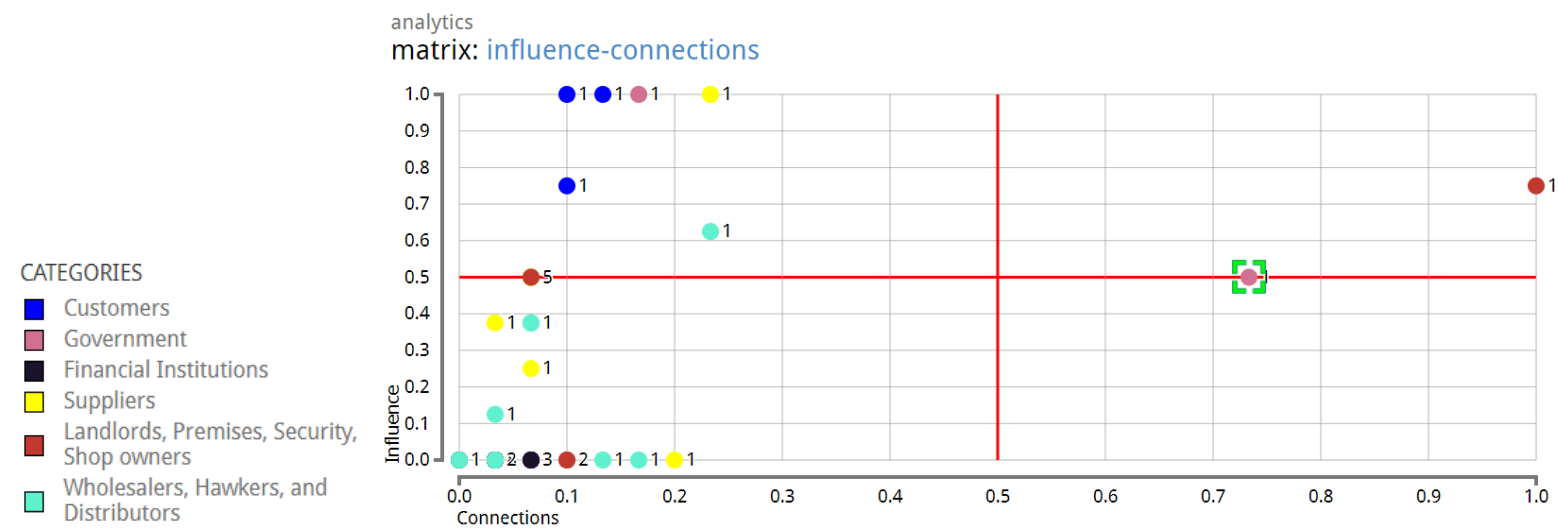

Figure 16: Influence-Connection matrix for participants who are new duka managers, from Kawangware

- $\quad$ Social network analysis metrics: Closeness and Betweenness

- Closeness: City council, Unilever, Small/Medium Business 13, and shop owners, Small/Medium Business 25 , were most closely linked to all actors in the network. This network was close-knit with many close connections across actors. Chamas and Small/Medium Business 21 had the lowest closeness factor while regular customers, saccos (credit cooperatives), shared the next to lowest closeness factor.

- Betweenness: City council and shop owners, played the most important connecting roles by linking other actors that may not necessarily have relationships with one another. Twenty-nine actors shared the lowest betweenness factor. 
Table 7: Summary of Net-Map results for actors, connections, perceived influence, and connectedness, by study site

\begin{tabular}{|c|c|c|c|c|}
\hline \multicolumn{5}{|c|}{ UJoin } \\
\hline & \multicolumn{2}{|c|}{ Kibera } & \multicolumn{2}{|c|}{ Kawangware } \\
\hline & New Managers & Experienced Managers & New Managers & $\begin{array}{c}\text { Experienced } \\
\text { Managers }\end{array}$ \\
\hline \# Actors & 36 & 37 & 38 & 37 \\
\hline \# Connections & 172 & 191 & 64 & 95 \\
\hline $\begin{array}{l}\text { High Influence and Many } \\
\text { Connections }\end{array}$ & Shop owners & Shop owners & $\begin{array}{l}\text { Shop owners, City } \\
\text { Council }\end{array}$ & Shop owners \\
\hline $\begin{array}{l}\text { High Influence and Few } \\
\text { Connections }\end{array}$ & $\begin{array}{l}\text { Customers } \\
\text { Government }\end{array}$ & Customers & City Council & None \\
\hline $\begin{array}{l}\text { Low Influence and Many } \\
\text { Connections }\end{array}$ & City Council & None & None & None \\
\hline $\begin{array}{l}\text { Low Influence and Few } \\
\text { Connections }\end{array}$ & $\begin{array}{l}\text { Financial Institutions, } \\
\text { Wholesalers } \\
\text { Suppliers, Promoters, } \\
\text { Manufacturers } \\
\text { Customers }\end{array}$ & $\begin{array}{l}\text { Suppliers, Promoters, } \\
\text { Manufacturers } \\
\text { Wholesalers } \\
\text { Financial Institutions }\end{array}$ & $\begin{array}{l}\text { Suppliers } \\
\text { Wholesalers } \\
\text { Hawkers } \\
\text { Distributors }\end{array}$ & $\begin{array}{l}\text { Wholesalers } \\
\text { Hawkers } \\
\text { Distributors } \\
\text { Financial } \\
\text { institutions }\end{array}$ \\
\hline
\end{tabular}

\section{Discussion}

Net-maps were created by members of two initiatives, UAfya and UJoin, residing in two informal settlements, Kibera and Kawangware, in Nairobi, Kenya. The results are discussed for each program and study site, with emphasis on similarities and differences in actors and linkages.

\subsection{UAfya}

Among communities of shoppers in Kawangware, a larger number of actors (average of 30) were identified compared to Kibera (average of 25). The groups in Kawangware also identified a significantly larger number of links (average of 167) compared to Kibera (average of 88). The number of links perceived as strong was also much higher in the maps completed by participants in Kawangware (average of 93) compared to the maps completed by participants in Kibera (average of 46). The results show that Kawangware is a tighter and stronger community for business and relationships. This may be a result of economic agency as Kawangware residents have slightly higher income and possibly more economic relationships and transactions.

In both Kibera and Kawangware, the younger participants identified far fewer perceived connections than older participants. It is noteworthy that in Kawangware, the younger participants perceived there were more connections than the older participants in Kibera. The older participants in Kawangware and Kibera shared more background about actors, explained arguments for drawing links, and provided more rationale for rating actor influence and alignment than the younger participants. This is not surprising given they have more experience to share, and have more, and older, children.

\subsubsection{Highly influential and well-connected actors}

In both locations family and friends were perceived to be highly influential and closely connected. Business companies, community institutions, and media also were highly influential and well-connected actors in Kawangware, however in Kibera, it was health practitioners and media type actors who had this classification. This is not unexpected as the UAfya initiative is a health-focused program with family-related themes for new and young mothers. During pregnancy and childcare, family and health workers have a more prominent role in the lives of new mothers and are potential influencers of knowledge and behavior. Younger participants from Kibera identified the media as having high influence and many connections. This is not unexpected as media is an important source of information, entertainment, and social networking among youth globally today. 
Schools and teachers were generally considered to be highly influential and well connected. School personnel, especially teachers but including athletic coaches and other support staff, were considered highly influential and highly connected, especially with the girl child.

In contrast, older UAfya participants from Kibera identified the health practitioner as an influential and connected actor. It may be that older participants have already made connections with health workers since Kibera has been a major target of development and philanthropic interventions while Kawangware has not. It was also noteworthy that actors belonging to formal institutions such as government officials and teachers were perceived to have higher levels of influence, while in contrast, midwives and traditional healers had contact with many UAfya members, but were assigned a low level of influence.

\subsubsection{Highly influential actors with few connections}

Social communities and community institutions, such as CBOs and NGOs were perceived to be highly influential actors with few connections, however, this result differed by study site and age. Specifically, this result was endorsed by participants from Kawangware and among older participants from Kibera. Younger UAfya participants from Kibera identified health practitioners as having high influence but few connections, and this may perhaps reflect their own needs and priorities as young and pregnant mothers-to-be, to make connections with health workers. This finding may also be in part influenced by personal experiences with outreach work in the community, or that younger individuals in Kibera do not see value in connections between health and business communities.

Nonetheless, this is an important finding that shows community institutions for business and health may be valued by some UAfya members and implies also that there may be untapped potential for these actor types to influence behaviors of community members. Perceptions of poor community connections with health practitioners and community institutions may be translated into a need for the UAfya community in Kibera.

\subsubsection{Well-connected actors with low influence}

Older participants in Kawangware perceived that the government was well-connected but lacked influence within the community, while younger participants from Kibera identified community institutions as being connected but uninfluential. This finding may underlie a credibility issue with community-based organizations among younger individuals in Kibera and warrants further exploration to support the development of positive community attitudes towards business groups that may be established in the future to support local entrepreneurs. One issue may be the lack of sustainability of community institutions. Another aspect could be "poverty tourism" in Kibera where outsiders and their programs come and go frequently. The youth, unlike their parents, may feel that accepting the narrative of these outside groups is undignified; they do not want to be labeled as 'hopeless' and in need of foreign handouts.

\subsubsection{Unconnected actors with low influence}

Actors in this category are disengaged from the UAfya community, and for both study sites, included government entities, business partners, and some NGOs. These actors included the Chamas (women's groups) who seldom talk about health issues, and spouses who were conspicuously absent from the maps. There were different views about the level of influence of Mama Mbogas (informal vegetable sellers) and their alignment with UAfya goals. However, they were frequently discussed in relation to the creation of the maps and could be engaged to further TRANSFORM goals. Safety issues in some sections of the Kibera community may underlie decreased penetration and visibility by the business community and business support companies, in turn, limiting opportunities for community interactions with vendors, and supporting companies.

\subsection{UJOIN}

The communities of shopkeepers in Kibera and Kawangware are similar in terms of the average number of actors identified (37.5 in Kawangware and 36.5 in Kibera). However, the average number of links perceived as strong was much higher in the maps completed by participants in Kibera (107) compared to the maps completed by participants in Kawangware (22). While shoppers (UAfya) in Kawangware were more close-knit than their counterparts in Kibera, a similar observation was not found among shopkeepers (UJoin) in Kawangware. This may be due to the physical proximity that shopkeepers have with one another in Kibera. In Kibera, there is a greater tendency for shopkeepers to rely more on each other, and borrow stock from each other, co-operate on delivery of stock, and help each other apply for permits. This leads to increased interaction and co-operation that strengthens social bonds and relationships. 
In both Kibera and Kawangware, UJoin groups that had been managing a duka for a longer period provided more depth about the actors, links, influence, and alignment than the younger segments. This is not surprising given they have more experience to share.

\subsubsection{Highly influential and well-connected actors}

The UJoin participants overwhelmingly perceived that their peers were the most influential and had the most connections. The perceptions ascribed to established and new shop owners combined with the relative absence of other actors with similar levels of influence suggest that the best way to spread behaviors in the UJoin community is from within their tight-knit network using early adopters and change agents.

\subsubsection{Highly influential actors with few connections}

The local government, especially the city council, was generally perceived to be more influential and have more connections. They deal with regulation and are positioned to influence behavioral matters related to health. Overall, the local government officials, including the Nairobi city council, health officers, and officials who regulate the commerce and the media, were rated as highly influential and have a high number of connections. This presents significant room for the city council to enhance work that provides policy or regulatory support to give dukas credibility as health agents.

Unilever is widely respected because they share information about the products they sell. Other manufacturers do not offer the same level of service. Manufacturing companies, especially Unilever, were consistently recognized as providing important health information about the health products they sell. Engaging other manufacturers to adopt similar practices would be welcome to the duka community.

\subsubsection{Well-connected actors with low influence}

Only one group (new managers in Kibera) identified an actor (the city council) who was well connected but who had low influence. This may be that newer managers are not yet experienced in their role to recognize how the city council may influence commerce. Alternatively, the city council may spend less time and give less attention to newer managers when compared to experienced managers. In this scenario, low levels of recognition between the two groups create a vicious cycle.

\subsubsection{Unconnected actors with low influence}

Managers from all four groups listed similar actors as having low influence and low connections. These actors included wholesalers, suppliers, distributors, who - with the exception of Unilever - were perceived to spend little time explaining the features of products that could improve customer health, with managers. Another actor that was frequently mentioned in this quadrant was financial institutions; financial institutions may be viewed negatively to reflect the difficulty of obtaining business loans and credit.

Comparison of group results

\section{Recommendation}

UAfya and UJoin have different goals and, by and large, the participants representing these initiatives discussed different actor types and actors when it came to who influenced decisions around healthy behaviors. An exception is the inclusion of government/city council in the maps created by both UAfya and UJoin groups. Despite being the only common actor/actor type, the two participant groups assigned government and city council different levels of influence and numbers of connection (Tables 4 and 7). This speaks to the importance of government/city council but also suggests a gap in perceptions relating to the relationships that government actors have with the businesses they help regulate.

The implications of the results for further research and for programs and policy are discussed in this section.

\subsection{Recommendations for programs}

The influence and connection matrices were assessed with existing knowledge in mind. Therefore, actors who had the highest scores - those furthest to the top right corner - were not automatically proposed as actors to engage with. These actors may have been either too vaguely defined (as in the case with friends and family or media in the UAfya maps) or already highly engaged (such as established dukas in the UJoin maps). 
Recommendations are organized according to general categories identified in a related literature review and case study series of micro-enterprises using digital communities to promote healthy behaviors. The five categories for scaling are competitiveness, collaboration, communication, capacity, and capability.

When considering competitiveness, we found that the City Council is highly influential but that dukas are not perceived as credible health agents. Our recommendations based on these findings are to help the City Council bridge untapped potential as a health system enabler. This could be done through the exploration of policy or regulatory tools.

In collaboration, we found that teachers are overlooked actors and they have credibility but they are not well connected to health actors. We recommend establishing a link between teachers and health providers. We also suggest leveraging teachers' influence on kids. In these communities, parents often send their kids to buy small items from dukas. Programs that support and increase the capacity of younger participants to develop efficacy to forge more and tighter linkages with other actors and services for the benefit of their business is also recommended. These may include peer-to-peer mentoring programs and opportunities to collaborate with and learn from more experienced peers, to increase skills and efficacy among younger duka owners. Strategies to improve working relationships with institutions that support micro-enterprise, especially financial institutions, and wholesalers, also is needed. In addition, government entities and sectors, including city council, had high influence but low linkages with the community of duka owners. Improving perceptions and image of government actors and providing opportunities for positive engagement and successful endeavors with the duka owners may be beneficial to integrating duka enterprises into mainstream retail activity and for sustaining scaled-up programs.

In communication we found that UAfya and UJoin members have knowledge they are willing to share with each other. We also found that there was limited consensus on what UAfya and UJoin means. Our recommendation is to amplify UAfya and UJoin brand identities and communication strategy. Leveraging the role of the media in promoting brand identity may be attractive to younger dukas managers/owners who engage more with media channels. Communication about products was limited between distributors and the dukas. Only one distributor provided education and messaging guidance that the retailers could be pass on to the consumer.

In capability we found that UAfya and UJoin have varying or value propositions. Prioritizing key opportunities on the consumer path from poverty to prosperity will likely be an attractive proposition for members of these groups, in turn garnering interest and increased engagement with platforms.

These recommendations support the vision for scale-up of the UJoin and UAfya programs: accreditation and branding of a novel type of duka, who is trained and knowledgeable, and provides high-quality services that includes training to meet basic health information needs of patrons. This accredited duka would foster a new type of retailer that provides basic health information to improve customer health while also selling more health products and benefiting the bottom line.

\subsection{Recommendations for further research}

To our knowledge, this is the first study to identify and examine who influencers duka owners' business practices. Additional social science research may provide more detailed insights on the nature of the relationships identified in this study. The individuals and linkages participants identified have the potential to be leveraged to strengthen new programs such as broader interventions to support micro-retailers and new mothers. For instance, qualitative studies to increase understanding of the factors influencing the role of health workers in the community will be important to a program aiming to use dukas as health advocates. Qualitative research might further explore why some actors with perceived high influence are poorly connected within the community of dukas and young mothers, and why government entities have low influence and connections with this community. Results may provide valuable insights for salient and culturally appropriate program design. Strategies that support access to, and networks with these actors, may strengthen the UAfya and UJoin communities.

Lastly, additional research among the larger population of micro-retailers, and that uses random sampling processes to support generalization of findings, may also both validate and expand on these findings, and make program strategies more applicable to the larger group of micro-retailers in Kenya. 


\subsection{Recommendations for policy}

For the construct of capacity, it was surprising to find that duka owners receive health information from their customers. Developing a government credential program to help build duka owner credibility as health information agents in their communities. It may also be beneficial for increasing knowledge and promoting positive health behavior change in underserved communities. Policies that encourage intersectoral collaboration social enterprise initiatives with duka owners such as joint ventures between the business, health, youth development, and education sector will be beneficial in synergizing the potential contributions of duka owners to education and health activities in their communities.

\section{Limitations}

While the results have provided several useful findings for scaling up programs for micro-retailers, they should be interpreted in consideration of the following limitations.

First, the purposeful convenience sample, while theoretically sound, precludes the ability to generalize the results beyond the two communities and to the wider population. It is possible that other micro-retailers who were not invited to participate or those who refused to participate in the activity, may have different demographics, perceptions, connections, and experiences from those who did participate. In addition, the results are limited to the duka owners that are registered with UJoin and UAfya rather than the larger community of duka owners.

Second, the results are based on self-reported perceptions and experiences that may be subject to recall and social desirability biases. The participatory process, member differences within groups, and group dynamics to derive the maps may also have influenced participant responses and introduced bias. Nevertheless, precautionary measures implemented during field work to ensure that participants felt comfortable within groups to provide objective responses, such as disaggregating groups by sex and age, and objective moderation of the group work, likely minimized the risk for these biases.

\section{Conclusions}

A net map activity was conducted among members of the UJoin and UAfya digital platforms in Nairobi Kenya, with the aim of exploring and understanding potential frameworks for establishing digital-based communitydriven partnerships with the private sector for health promotion through behavior change. Results showed that there are various actors that influence UAfya and UJoin platform members, and the level of influence and connectedness varies by age, sex, and experience (with business and motherhood) of program beneficiaries. Gendered approaches may be needed to tailor digital program design to the needs of different sub-groups using digital innovations. The results also showed that duka owners are connected to actors with potential to build their capacity to promote healthy behaviors in their communities in the course of their daily business activities. When scaling-up digitally-based knowledge, capacity-building, and support programs, planners must understand the perspective of the audience in terms of who the key actors are that support them on a daily basis, perceived influence of different actors, factors that connect the audience to actors, each other, and to program services, as well as what hampers relationships and connections.

\section{Acknowledgments}

Nora Bergin, Senior Project Manager, Every1Mobile

Abi Gleek, Head of Programme Design, Every1Mobile

Humphrey Mwaura, Project Coordinator, Every1Mobile

Michelle Mulemi, Community Manager, Every1Mobile

Elizabeth Wakuraya, Community Manager, Every1Mobile

Olivia Chan, student, Johns Hopkins University

\section{References}

Campbell N., Schiffer E., Buxbaum A., McLean, E., Perry, C., Sullivan, T., 2014. Taking knowledge for health the extra mile: participatory evaluation of a mobile phone intervention for community health workers in Malawi. Global Health, Science and Practice, 2(1), pp. 23-34. Datamuse, 2020. Datamuse. [software]. Available at https://www.datamuse.io/ [Accessed 12 December 2019.] 
Demmlera K., Ecker O., and Qaim M., 2018. Supermarket shopping and nutritional outcomes: a panel data analysis for urban Kenya. World Development. 102(2018), pp. 292-303. Available at: <https://www.sciencedirect.com/science/article/pii/S0305750X17302486> [Accessed 07 October 2020].

Eysenbach G., 2007. From intermediation to disintermediation and apomediation: new models for consumers to access and assess the credibility of health information in the age of Web2.0. Studies in Health Technology and Informatics, 129(Pt 1), pp.162-166.

Goh J.M., Gao G. and Agarwal R., 2016. The creation of social value: can an online health community reduce rural-urban health disparities? MIS Quarterly, 40(1), pp. 247-263.

Harlan S., Sullivan T., and Hailegiorgis S., 2013. Mapping networks to improve knowledge exchange among family planning and reproductive health organizations in Ethiopia. Knowledge Management for Development Journal. 9(2), pp. 140161 Available at: <https://www.km4djournal.org/index.php/km4dj/article/view/163/231> [Accessed 07 October 2020].

Hendrickx H., Bergin N., GleekA., Wakuraya E., Fulcher A., and Wright R.,2018. U Afya: A digital community for young mothers to support health and hygiene behaviour change in low income areas in urban Nairobi. Research Gate. Available at:

<https://www.researchgate.net/profile/Hilde_Hendrickx/publication/324601887_U_Afya_A_digital_community_for young_mothers_to_support_health_and_hygiene_behaviour_change_in_low_income_areas_in_urban_Nairobi/links /5ad85aad458515c60f5899fc/U-Afya-A-digital-community-for-young-mothers-to-support-health-and-hygienebehaviour-change-in-low-income-areas-in-urban-Nairobi > [Accessed 07 October 2020].

Mahmood H., Suleman Y., Hazir T., Akram D., Uddin S., Dibley M., Abassi S., Shakeel A., Kazmi N., Thow A., 2017. Overview of the infant and young child feeding policy environment in Pakistan: Federal, Sindh and Punjab context. BMC Public Health. 17. Available at: <https://bmcpublichealth.biomedcentral.com/articles/10.1186/s12889-017-4341-5> [Accessed 07 October 2020].

Massaro M., Dumay J. and Bagnoli C., 2019. Transparency and the rhetorical use of citations to Robert Yin in case study research. Meditari Accountancy Research, (27)1, pp. 44-71.

Mwiti L., 2018. Family-owned dukas suffer major losses, closures in 2017. Standard Media. Available at: <https://www.standardmedia.co.ke/financial-standard/article/2001290114/family-owned-dukas-suffer-major-lossesclosures-in-2017> [Accessed 07 October 2020].

Presch G., Dal Mas F., Piccolon D., Sinik M. and Cobianchi L,. 2020. The World Health Innovation Summit (WHIS) platform for sustainable development. From the digital economy to knowledge in the healthcare sector. In: P. Ordonez de Pablos and L. Edvinsson (Eds). Intellectual capital in the digital economy. London: Routledge. pp. 19-28.

Tambo E., Madjou G., Mbous Y., Olalubi O.A., Yah C., Adedeji A.A. and Ngogang J.Y., 2016. Digital health implications in health systems in Africa. European Journal of Pharmaceutical and Medical Research, (3)1, pp.91-93.

TechnoServe. 2019. A day in the life: supporting duka owners in Kenya. TechnoServe. Available at: $<$ https://www.technoserve.org/blog/a-day-in-the-life-supporting-duka-owners-in-kenya> [Accessed 07 October 2020].

TechnoServe. 2020. Transforming communities through micro-retailers. TechnoServe. Available at: <https://www.technoserve.org/blog/smart-fixes-for-smart-shops-transforming-communities-through-micro-retailer> [Accessed 07 October 2020].

UNICEF. 2019a. Maternal mortality. UNICEF. Available at: <https://data.unicef.org/topic/maternal-health/maternalmortality > [Accessed 07 October 2020].

UNICEF. 2017. Situation analysis of children and women in Kenya. UNICEF. Available at: <https://www.unicef.org/kenya/media/136/file/SITAN-report-2017-pdf> [Accessed 07 October 2020].

UNICEF. 2019b. Water, sanitation and hygiene. UNICEF. Available at: <https://www.unicef.org/kenya/water-sanitationand-hygiene $>$ [Accessed 07 October 2020].

UJoin, 2019. Transform. [online] Available at: <https://ujoin.co.ke.> [Accessed 23 September 2019].

Wakefield MA., Loken B., and Hornik RC., (2010). Use of mass media campaigns to change health behaviour. Lancet (3769748), pp. 1261-1271.

Wasko M., Faraj S., 2000. It is what one does: why people participate and help others in electronic communities of practice. The Journal of Strategic Information Systems. 9. pp.155-173.

Waweru A., 2018. Success on every corner: how mom-and-pop shops can drive growth in Africa. Business Fights Poverty. Available at: <https://businessfightspoverty.org/articles/success-on-every-corner-how-mom-and-pop-shops-candrive-growth-in-africa> [Accessed 07 October 2020].

Wright RL., Gleek A., Bergin N., Algy W., Sohail A., . 2019. Using 'Theories of Change' and responsive feedback to design a digital service business for patent and proprietary medicine vendors in Nigeria. Gates Open Research, 3. [online] Available at: <https://www.ncbi.nlm.nih.gov/pmc/articles/PMC6993493/pdf/gatesopenres-3-14138.pdf> [Accessed 07 October 2020].

Yin R.K., 2014. Case Study Research: Design and Methods. Thousand Oaks, CA: Sage Publications. 